\title{
Intensive speech and language therapy in patients with chronic aphasia after stroke: a randomised, open-label, blinded-endpoint, controlled trial in a health-care setting
} DOI:

10.1016/S0140-6736(17)30067-3

\section{Document Version \\ Accepted author manuscript}

Link to publication record in Manchester Research Explorer

Citation for published version (APA):

FCET2EC Study group (2017). Intensive speech and language therapy in patients with chronic aphasia after stroke: a randomised, open-label, blinded-endpoint, controlled trial in a health-care setting: A randomised, openlabel, blinded-endpoint, controlled trial in a health-care setting. The Lancet, 389(10078), 1528-1538. https://doi.org/10.1016/S0140-6736(17)30067-3

\section{Published in:}

The Lancet

\section{Citing this paper}

Please note that where the full-text provided on Manchester Research Explorer is the Author Accepted Manuscript or Proof version this may differ from the final Published version. If citing, it is advised that you check and use the publisher's definitive version.

\section{General rights}

Copyright and moral rights for the publications made accessible in the Research Explorer are retained by the authors and/or other copyright owners and it is a condition of accessing publications that users recognise and abide by the legal requirements associated with these rights.

\section{Takedown policy}

If you believe that this document breaches copyright please refer to the University of Manchester's Takedown Procedures [http://man.ac.uk/04Y6Bo] or contact uml.scholarlycommunications@manchester.ac.uk providing relevant details, so we can investigate your claim.

\section{OPEN ACCESS}




\title{
Published online in The Lancet on February 27, 2017
}

\section{http://dx.doi.org/10.1016/So140-6736(17)30067-3}

(Please note: Due to editorial changes by the journal, the manuscript title of the published version has been altered to:

'Intensive speech and language therapy in patients with chronic aphasia after stroke: a randomised, open-label, blinded-endpoint, controlled trial in a health-care setting')

Intensive speech and language therapy improves everyday verbal communication in chronic post-stroke aphasia:

A prospective randomised controlled healthcare trial (FCET2EC)

\begin{abstract}
Caterina Breitenstein ${ }^{1 *}$,
Tanja Grewe ${ }^{2}$, Agnes Flöel3 ${ }^{3}$ Wolfram Ziegler ${ }^{4}$, Luise Springer ${ }^{6+}$, Peter Martus ${ }^{5}$, Walter Huber ${ }^{6}$, Klaus Willmes7, E. Bernd Ringelstein ${ }^{1}$, Karl Georg Haeusler ${ }^{8}$, Stefanie Abel7,9, Ralf Glindemann ${ }^{10}$, Frank Domahs ${ }^{11}$, Frank Regenbrecht ${ }^{12}$, Klaus-Jürgen Schlenck ${ }^{13}$, Marion Thomas ${ }^{1}$, Hellmuth Obrig ${ }^{12}$, Ernst de Langen ${ }^{14}$, Roman Rocker ${ }^{1}$, Franziska Wigbers ${ }^{1}$, Christina Rühmkorf ${ }^{1}$, Indra Hempen ${ }^{1}$, Jonathan List 3 , \& Annette Baumgaertner ${ }^{2}$
\end{abstract}

for the FCET2EC Study group (individual names of non-author contributors are listed in the Suppl. Information)

${ }^{1}$ Dept. of General Neurology (formerly: Dept. of Neurology), University of Muenster, Germany (C Breitenstein PhD, Prof EB Ringelstein MD, M Thomas MA, R Rocker MD, F Wigbers cand med, C Rühmkorf cand med, I Hempen BA)

${ }^{2}$ Faculty of Health and Social Sciences, Fresenius University of Applied Sciences, Idstein/Hamburg, Germany (Prof T Grewe PhD, Prof A Baumgaertner PhD) 
3 NeuroCure Clinical Research Centre, Centre for Stroke Research Berlin, \& Dept. of Neurology, Charité - Universitätsmedizin Berlin, Germany

(Prof A Flöel MD, J List MD)

4 Clinical Neuropsychology Research Group (EKN), Institute of Phonetics and Speech Processing, Ludwig-Maximilians-University, Munich, Germany (Prof W Ziegler PhD)

5 Institute for Clinical Epidemiology and Applied Biostatistics, University of Tuebingen, Germany (Prof P Martus PhD)

${ }^{6}$ Clinical and Cognitive Neuroscience, Dept. of Neurology, University Hospital RWTH Aachen, Germany (L Springer PhD, Prof W Huber PhD)

7Neuropsychology, Dept. of Neurology, University Hospital RWTH Aachen, Germany (Prof K Willmes PhD, Prof S Abel PhD)

${ }^{8}$ Centre for Stroke Research Berlin \& Dept. of Neurology, Charité - Universitätsmedizin Berlin, Germany (KG Haeusler MD)

${ }^{9}$ School of Biological Sciences, University of Manchester (GB) (S Abel)

${ }^{10}$ Neuropsychological Department, Bogenhausen Hospital, Munich, Germany (R Glindemann PhD)

${ }^{11}$ Institute of Germanic Linguistics, University of Marburg, Germany (Prof F Domahs PhD)

${ }^{12}$ Clinic of Cognitive Neurology, University of Leipzig, \& Max Planck Institute for Cognitive and Brain Sciences, Leipzig, Germany (F Regenbrecht MA, Prof H Obrig MD)

13 m \& i Fachklinik Enzensberg, Fuessen, Germany (KJ Schlenck PhD)

14 Reha-Centre Passauer Wolf, Bad Griesbach, Germany (E deLangen PhD)

+ deceased in August 2011 (L Springer PhD)

Corresponding author:

Dr. Caterina Breitenstein

Dept. of General Neurology with Institute of Translational Neurology

University of Muenster

Albert-Schweitzer-Campus 1, Bldg. A1

D-48149 Muenster, Germany

caterina.breitenstein@uni-muenster.de 
Abstract

\section{Background}

To date, aphasia therapy guidelines recommend intensive speech and language therapy (SLT) for chronic post-stroke aphasia, but large-scale "class 1" randomised controlled trials (RCT) on treatment effectiveness are lacking. This multi-centre, parallel group, superiority, open blinded-endpoint RCT examined whether intensive SLT under routine clinical conditions improves verbal communication in daily life situations in chronic post-stroke aphasia, and whether treatment effects persist over a period of six months.

\section{$\underline{\text { Methods }}$}

In 19 German in- or outpatient rehabilitation centres, patients aged $\leq 70$ years with chronic post-stroke aphasia were randomly assigned to either $\geq 3$ weeks of intensive SLT (intervention group; $\mathrm{n}=78, \geq 10 \mathrm{~h}$ of SLT/week) or three weeks deferral of intensive SLT (control group; $n=78$ ). A computer-generated permuted block randomisation, stratified by treatment centre, was administered by an external biostatistician; consecutive inclusion codes were kept in sealed opaque envelopes. Primary endpoint was the change in verbal communication effectiveness in everyday life scenarios (blinded offline-evaluation of the Amsterdam Nijmegen Everyday Language Test/ANELT A-scale) from pre to post 3 weeks of intensive SLT compared to 3 weeks deferral of intensive SLT. All analyses were performed in the intention-to-treat population ( $\geq 1$ day of intensive SLT or waiting period). This study has been registered with ClinicalTrials.gov (Trial identifier: NCTo1540383, status: closed).

\section{$\underline{\text { Results }}$}

One-hundred-fifty-eight patients were assigned between April 2012 and May 2014, with 156 patients being analysed (one dropout per group prior to intervention). Verbal communication significantly improved by 10 percent after intensive SLT (mean difference: 2.61 points+/- SD 4.94, 95\% CI: 1.49 to 3.72 ), but not after the waiting period (mean difference: -0.03 points +/- SD 4.04; 95\% CI: -0.94 to 0.88; group difference: Cohen's d: 0.58). Group differences were not moderated by patient-, stroke-, or therapy-related factors. 
Treatment effects remained stable for at least six months (if pooled across groups: $d$ $=0.45)$.

\section{$\underline{\text { Conclusions }}$}

Three weeks of intensive SLT significantly enhanced verbal communication in chronic post-stroke aphasia, providing an effective evidence-based treatment approach in the middle-aged population. Future studies should examine the minimum SLT intensity required for significant treatment effects, and determine whether treatment effects cumulate over repeated intervention periods.

\section{Funding}

German Ministry of Education and Research (BMBF) and the German Society for Aphasia Research and Treatment (GAB). 


\section{Research in context}

\section{Evidence before this study}

We searched PubMed and PsychInfo on June 28, 2016, for manuscripts published in English from inception until June 28, 2016, with the terms "stroke rehabilitation" combined with the terms "aphasia" or "outcome" or "evidence-based practice", or "activities of daily living". We also searched the term "stroke" in combination with "incidence rates" or "health care costs“, respectively. We had no additional inclusion or exclusion criteria for the studies searched.

For decades, it had been postulated that verbal communication improvements cannot be achieved in chronic post-stroke aphasia. Several RCTs have been conducted on the effectiveness of speech and language therapy (SLT) in this population, yet the reported results were inconclusive. Prior RCTs were hampered by methodological limitations: sample sizes were generally small (less than 20 patients per group), therapy administration was not intensive (i.e., $<5 \mathrm{~h} /$ week), and/or long-term therapy outcomes were not reported. Recently, however, meta-analyses and systematic reviews provided strong evidence that SLT, if administered with sufficient intensity ( $\geq 5 \mathrm{~h}$ /week), is effective even in the chronic stage post stroke. Despite this evidence derived from systematic reviews, patients with chronic post-stroke aphasia continue to be frequently denied access to SLT services. The main reason is the lack of at least one large-scale multi-centre RCT with sound statistics demonstrating lasting improvements of everyday language function after intensive SLT.

\section{Added value of this study}

To date, the multi-centre trial "From controlled experimental trial to=2 everyday communication/FCET2EC" represents the largest appropriately controlled prospective RCT on the effectiveness of intensive SLT compared to a no (or low intensity) SLT control condition in patients with chronic post-stroke aphasia. The findings provide statistically robust evidence for the superiority of 3-week intensive individualized SLT (10 h/week) compared to 3-week deferral of intensive SLT. Treatment effects remained stable across the follow-up period of six months. The study thus corroborates the results of prior underpowered studies suggesting a positive and lasting effect of intensive SLT. In contrast to previous studies in the field, which predominantly 
assessed performance in isolated linguistic functions with low ecological validity, the primary outcome of the FCET2EC trial addressed verbal communication in everyday life scenarios.

\section{Implications of all the available evidence}

In conjunction with the evidence derived from systematic reviews in the field, results of the FCET2EC trial justify the statistically sound conclusion that intensive SLT is an evidence-based intervention for chronic post-stroke aphasia. Compared to previous studies, inclusion criteria were liberal with respect to stroke etiology (ischaemic, hemorrhagic and subarachnoid hemorrhage), aphasia type, and aphasia severity, allowing the generalization of the trial's results to the population of post-stroke aphasia patients aged $\leq 70$ years. Furthermore, no participant dropped out of the 3week intensive individualized agreed-best clinical practice intervention which had been provided under routine clinical conditions. It is thus not required to further demonstrate the intervention's feasibility for routine health care settings. The FCET2EC results may fundamentally change the allocation of rehabilitation resources for chronic post-stroke aphasia. 


\section{Introduction}

Persistent aphasia affects about 20\% of all stroke patients (1). Being one of the most devastating symptoms in stroke survivors (2;3), aphasia predicts the degree of rehabilitation services required (4) and failure in returning to work (5). With increasing survival rates after the initial stroke (6), additional financial constraints are placed on health care providers, with aphasia contributing $\sim 8.5 \%$ of stroke-related healthcare costs during the first year post stroke (7).

Such dramatic consequences of post-stroke aphasia call for evidence-based effective interventions (8). Recent meta-analyses concluded that speech and language therapy (SLT) after stroke is effective even in the chronic stage, if administered with sufficient intensity (5-10 hours per week) (9-12). However, most of these studies rank below "level 2" according to the classification scheme of the Centre for Evidence-Based Medicine (http://www.cebm.net/ocebm-levels-of-evidence). The few high-quality studies had either small sample sizes, no untreated/low intensity control group (13-16), or low SLT intensity ( $<5$ hours/week) (17-20). Thus, large multi-centre randomised controlled clinical trials (RCT) on the effectiveness of intensive aphasia therapy with reliable and valid outcome parameters are urgently required.

The German multi-centre RCT "From controlled experimental trial to (=2) everyday communication" (FCET2EC) probed the effectiveness of $\geq 3$ weeks of intensive agreedbest-practice SLT in chronic (i.e. persisting for $\geq 6$ months) post-stroke aphasia compared to three weeks deferral of SLT (control group). Specifically, this clinical trial assessed whether intensive ( $\geq 10$ hours/week) best practice SLT translates into functional improvement of everyday verbal communication and better health-related quality of life up to six months post-intervention. We additionally examined the impact of patient-, stroke-, and therapy-related factors (see Suppl. Information) on the primary treatment effect. 


\section{Methods}

\section{Trial design:}

The trial design (Figure 1) was published previously (21) (open access download link: http://www.ncbi.nlm.nih.gov/pmc/articles/PMC3850954). The trial qualifies as a prospective randomised (equal randomisation to two arms), open, blinded endpoint (PROBE), multi-centre, stratified (according to centre), waiting-list controlled, parallel-group design to demonstrate the superiority of 3-week intensive SLT over 3week deferral of SLT (equal allocation ratio). SLT was provided in 19 German in- or outpatient rehabilitation sites specialised in stroke rehabilitation, treating a median of 688 stroke patients per year (reference year: 2013). As a control, deferral of intensive SLT was considered most appropriate because any "active" control condition bears the risk of providing language stimulation (17). No major changes in methodology were required after the trial had started.

The study coordination centre was based at the General Neurology Department of the University Hospital Muenster, Germany. Statistical analyses were performed by an external biometrician (P.M., University of Tuebingen, Germany). The Trial Steering Committee (TSC) - comprising six members (2 neurologists, 1 neurolinguist, 1 neuropsychologist, 1 biostatistician, 1 patient delegate) - monitored study progress during the 26 months of patient recruitment. Except for the patient delegate, the TSC members are scientific experts on stroke and aphasia treatment in Germany (see also 'Contributors'). All members were independent of the principal investigators, their employing organisations, funders, and sponsors. There were no planned interim analyses; the TSC had no access to the data before final analyses were completed.

The study was approved by the institutional review board of the Lead Trial Physician (A.F.) at the Charité-Universitätsmedizin Berlin, Germany (primary vote; identifier: EA1/234/11), as well as by the ten review boards of the participating centres (secondary votes). 


\section{Participants:}

To reflect realistic routine healthcare conditions, inclusion criteria were liberal: persistent aphasia as confirmed by the Aachen Aphasia Test (AAT) (22), lasting $\geq 6$ months after an ischemic or hemorrhagic stroke, age between 18-70 years, German acquired as first language, basic comprehension abilities and at least rudimentary attempts to verbally communicate (communication score $>0$ on the AAT spontaneous speech scale), and the ability to follow simple instructions ( $\geq 1$ correct response on the first 10 items of the AAT Token Test). Exclusion criteria comprised severe untreated medical conditions and severe uncorrected vision or hearing impairments, aphasia owing to traumatic brain injury (TBI) or neurodegenerative disease, or participation in an alternative intensive intervention to relieve stroke symptoms during the 4 weeks prior to enrolment. Pre- and post-therapy data were collected at treatment sites or patients' homes, whichever was more convenient for the patient.

SLT was provided as part of routine clinical care, funded by the patients' healthcare provider or retirement fund. All sites applied a uniform recruitment strategy. After routine referral to a given centre, potential study participants were contacted by phone by a centre representative. Sites carried log files documenting each eligible patient referred to the centre and, if applicable, reasons for not including the patient. After study termination, all log files were made available to the central study office. Reasons for non-inclusion of patients have been comprehensively listed in Figure 1. Every patient, and if required his or her legal representative, gave written informed consent before trial participation.

\section{Randomisation and masking}

Randomisation (computer-generated blockwise random sequence stratified by centre; consecutive inclusion codes for each centre kept in sealed opaque envelopes) and group allocation to either the immediate SLT group (I-SLT-G) or the waiting-list control group (WL-CG) were carried out by the trial biometrician P.M.. Group allocation for a given patient ID was faxed to the study coordination centre for implementation. The personnel in the study coordination centre had to be aware of the patients' group allocations to schedule the assessments accordingly, but was not involved in the assessments or the SLT intervention. 
Pre- and post-therapy assessments were administered by 40 external study assessors (all professional SL therapists) not otherwise involved in the study. All assessors were extensively trained in administration and scoring of the outcome measures and closely supervised by the trial-coordinator and the personnel of the study coordination centre during data acquisition. Patients and study assessors could not be masked with respect to group allocation because patients in the WL-CG had one additional baseline assessment (i.e., prior to and after their 3-week waiting period; see below) compared to the I-SLT-G. However, offline evaluation of the primary outcome measure (ANELT) was carried out by an independent endpoint committee of eight raters trained for this purpose and blinded with respect to group assignment and assessment (pre vs. post) by random labelling of the respective audio files (using the names of the planets of our galaxy). Data blinding was carried out in the study coordination centre.

For quality assurance, each data set was independently monitored in the study coordination centre by two research assistants not otherwise involved in the trial and blinded to group allocation; $100 \%$ of primary outcome and $30 \%$ of secondary outcome data were additionally checked by an external monitor.

\section{Procedures:}

Prior to the first patient enrolment, participating therapists were thoroughly trained in using the study SLT manual (Supplemental Information for details) and the monitoring/documentation forms, and were closely supervised by the authors of the manual (a subgroup of the study authors). The intervention was based on best-practice guidelines (Supplemental Information), combining linguistic and communicativepragmatic approaches individualized to the baseline profile of each patient. SLT was provided for $\geq 3$ weeks with $\geq 10$ hours/week and was offered by professional therapists in one-to-one and group therapy sessions, plus $\geq 5$ hours/week self-managed PCtraining targeting individual linguistic deficits. Selection of initial individual SLT targets was based on the patients' baseline linguistic and communicative-pragmatic performance (Supplemental Information). Daily SLT duration and contents were documented by the centres.

The WL-CG received an identical intensive SLT starting immediately after the 3-week waiting period. Because of the health care embedding of the trial, patients in the WLCG could continue conventional low intensity SLT in private practice during their 3- 
week waiting period (on average 1.5 hours/week, see Suppl. Table 1). Total rehabilitation duration depended on a patient's individual healthcare plan, but comprised $\geq 3$ weeks for all cases In Germany, most health care insurances currently limit aphasia rehabilitation to a period of three weeks. Our study design was adapted accordingly (critical treatment period: weeks 1-3). The decision to extend the rehabilitation period beyond three weeks is made by the health care funder, not by the therapist.

Patients could continue SLT during the follow-up period of six months, and the majority of patients did so at a level of $1.2 \mathrm{hrs} /$ week (see Suppl. Table 1).

Demographic, cognitive, speech, language, and clinical (based on medical records) characteristics were assessed in an initial screening session (Supplemental Information for details). Primary and secondary outcome assessments were carried out within three working days (a) prior to and after the 3-week intensive SLT for the ISLTG and (b) prior to and after the 3-week waiting period for the WL-CG. Additionally, the WL-CG was tested after the ensuing 3-week SLT. Both groups were reassessed six months [+/- 10 days] after termination of the 3 -week intensive SLT period.

A subgroup of 34 patients (pooled across groups) was granted $\geq 5$ weeks of intensive SLT by their respective health care providers. Outcome measures were additionally assessed within three working days after the entire (5-8 weeks) intensive SLT period for this subsample.

\section{Outcome measures}

The centrally assessed primary outcome measure was verbal communication effectiveness in ten everyday life situations employing the two parallel versions of the Amsterdam-Nijmegen Everyday Language Test (ANELT) A-scale (23). Versions I and II were counterbalanced across subsequent assessments of a given patient; $53 \%$ of the patients received version I first, for the remaining patients version II was used. ANELT assessments were audio-recorded for blinded off-line evaluation (see section on "masking”). All ANELT sessions of a given patient were rated by two of the eight raters (coupling of rater pairs across patients by a PC random algorithm, with the constraint that the eight raters evaluated comparable amounts of data sets). The interrater agreement of all eight raters was highly satisfactory (Krippendorff's alpha $=0 \cdot 81$ ). 
Each of the 10 ANELT scenarios of a given version was scored for its degree of verbal effectiveness (A-scale), ranging from score $1=$ "no relation to communicative scenario at all" to score 5 = "all information required for successful communication has been provided". For a given patient, the mean score of the two raters for each of the ANELT scenarios was computed. Mean scores for all 10 scenarios were then summarized into a total ANELT score (minimum score: 10, maximum score: 50). Primary endpoint was the ANELT change immediately post the 3 week intervention; long-term stability of the treatment effects over a 6-month period was analysed as secondary endpoint.

The following secondary outcome measures were centrally assessed:

- $\quad$ stroke severity [modified Rankin Scale (mRS)] (24);

- auditory intelligibility in everyday communication (ANELT B-scale) (23);

- impairment-specific language measures (Sprachsystematisches APhasieScreening/SAPS) (see Suppl. Information for details) assessing comprehension and production abilities in the core language domains of phonology, lexicon, and syntax;

- a standardized questionnaire assessing quality of life as viewed by the patient [Stroke and Aphasia Quality of Life Scale-39 (SAQOL-39) (25)];

- communication ratings by a significant other [Communicative Effectiveness Index (CETI) (26), assessed at baseline and at the 6-month follow-up;

- transfer to other cognitive functions [nonverbal learning: Nonverbal Learning Test (NVLT) (27)]; visual attention/executive functioning: Trail Making Test (TMT), versions A and B (28).

The study coordination centre had to be informed of adverse events (AEs) by the centres within $24 \mathrm{~h}$ of first occurrence. Unexpected or serious AEs had to be reported to the TSC which had the authority to halt recruitment or to cease the trial.

\section{$\underline{\text { Statistical analysis }}$}

A priori sample size calculation to detect a significant increase on the primary outcome measure (19) from before to after the 3-week intensive SLT with a statistical power of 0.90 , an estimated effect size of $0 \cdot 71$, and a two-sided alpha significance level of 0.05 yielded a sample size of $n=63$ patients/group. Anticipating a drop-out rate of 25 
percent, we planned to enrol $n=84$ patients per group during a 26-month recruitment phase.

The analyses of primary and secondary endpoints were performed in the intention-totreat (ITT) population, consisting of all randomised patients who received $\geq 1$ day of therapy or were $\geq 1$ day on the waiting list. Additional analyses performed in the treated per protocol (PP) population (I-SLT-G: $n=64$, WL-CG: $n=72$ ) yielded the same pattern of results and are not further reported here. Data of all 156 patients were complete for the primary analysis, not requiring data imputation. For normally distributed data parametrical methods were used. In case of non-normally distributed data, the Mann-Whitney U-test was used for group comparisons, and the Wilcoxon signed-rank test for pairwise intra-subject comparisons.

The primary analysis was based on an ANCOVA model with the ANELT A-scale score after the 3-week SLT or 3-week waiting period as dependent variable, treatment group (I-SLT-G, WL-CG) as independent variable, and baseline ANELT A-scale score as covariate. To assess possible moderator effects, interactions of treatment group with demographic, clinical, cognitive, and linguistic variables (Suppl. Information) were also analyzed. To assess demographic, cognitive, stroke- or aphasia-related predictors of the immediate treatment success (Suppl. Information), therapy effects of both treatment groups were pooled. The secondary outcomes were evaluated with the same statistical approach. No adjustment for multiple testing was applied to secondary analyses. Thus, analyses were not strictly confirmatory with the exception of the analysis for the primary endpoint.

All statistical analyses were conducted using IBM SPSS 22.

This study has been registered at ClinicalTrials.gov (trial identifier: NCTo1540383, status: closed; protocol information including the history of changes:

https://clinicaltrials.gov/ct2/show/NCT01540383).

\section{$\underline{\text { Role of the funding source }}$}

The funders of the study had no role in study design, data collection, data analysis, data interpretation, or writing of the report. The corresponding author had full access to all the data in the study and had final responsibility for the decision to submit for publication. 


\section{Results}

\section{$\underline{\text { Patient recruitment }}$}

During the recruitment period (April 1, 2012 to May 31, 2014), 158 patients were randomly assigned to the two groups ( $n=79$ each; see Figure 1$)$. One patient in each group was an early drop-out and excluded from further analyses. No patient was lost to the immediate assessment after SLT or after waiting, but one patient in each group (1\%) was lost prior to the 6-month follow-up. Eight patients experienced adverse events (AEs) during the SLT or waiting period unrelated to study participation (1 car accident, 2 common colds, 3 gastrointestinal or cardiac symptoms, 2 recurrent strokes). In total, patients received 3-10 weeks of SLT (median: four weeks), with 22:5-49 hours of intensive SLT within the first three weeks (median: 31 hours). 


\section{Flow of patient recruitment}
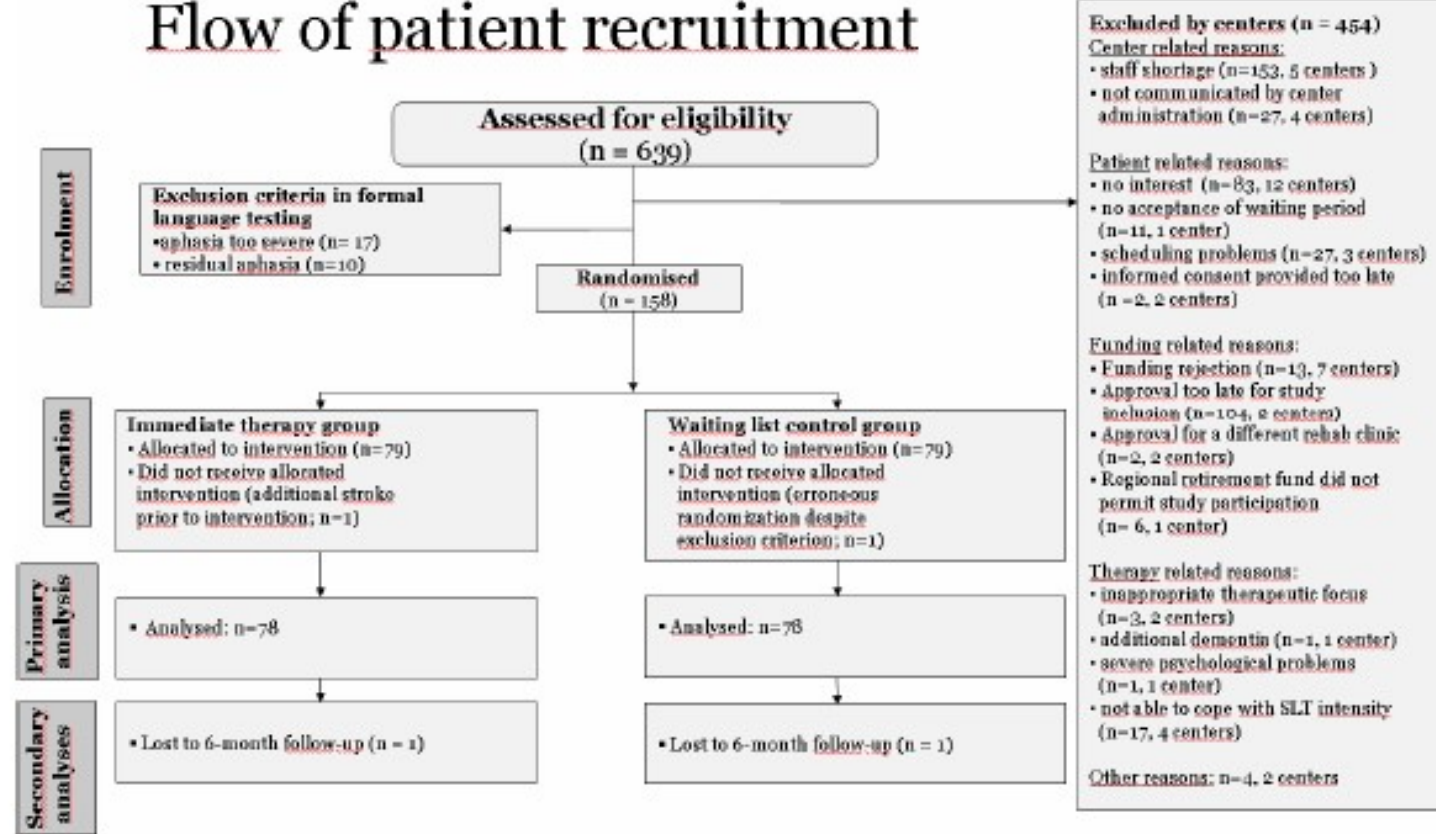

Qther reaseans: n-4, 2 centers

\section{FCET2EC study design}

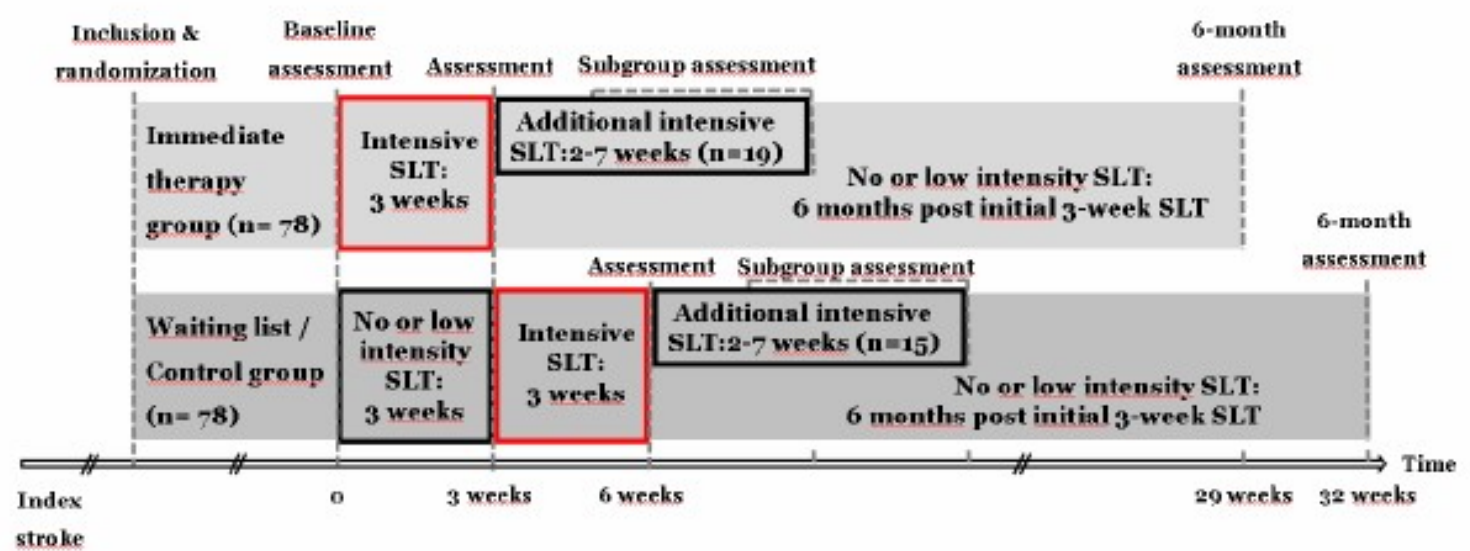

Figure 1, TOP: Patient flow during the 26 months of recruitment and the 6-month follow-up; BOTTOM: Study design showing the assessments for the two groups; SLT $=$ speech and language therapy

Baseline demographic and clinical characteristics are reported in Table 1/Suppl. Table

1. Groups did not differ regarding stroke- or aphasia-related variables except for a higher frequency of initial thrombolysis in the WL-CG (36\% versus 19\%). There was a 
trend towards a longer post-stroke time period in the I-SLT-G (medians: 43 versus 27 months).

\section{$\underline{\text { Primary analysis }}$}

Gains in verbal communication effectiveness from pre to post the 3-week intensive SLT (primary endpoint) versus 3-weeks of waiting were significantly larger in the I-SLT-G (mean difference: $2 \cdot 61+/-\mathrm{SD} 4 \cdot 94,95 \% \mathrm{CI}: 1 \cdot 49$ to $3 \cdot 72$ ) compared to the WL-CG (mean difference: -0.03 +/- SD 4.04; 95\% CI: -0.94 to 0.88; group difference: $\mathrm{p}<$ 0.001, Cohen's d = 0.58; see Figure 2 - left panel and Table 2). The group difference was independent of potential moderator variables, e.g. age or time post-index stroke (see Suppl. Information for the list of analysed moderator variables).

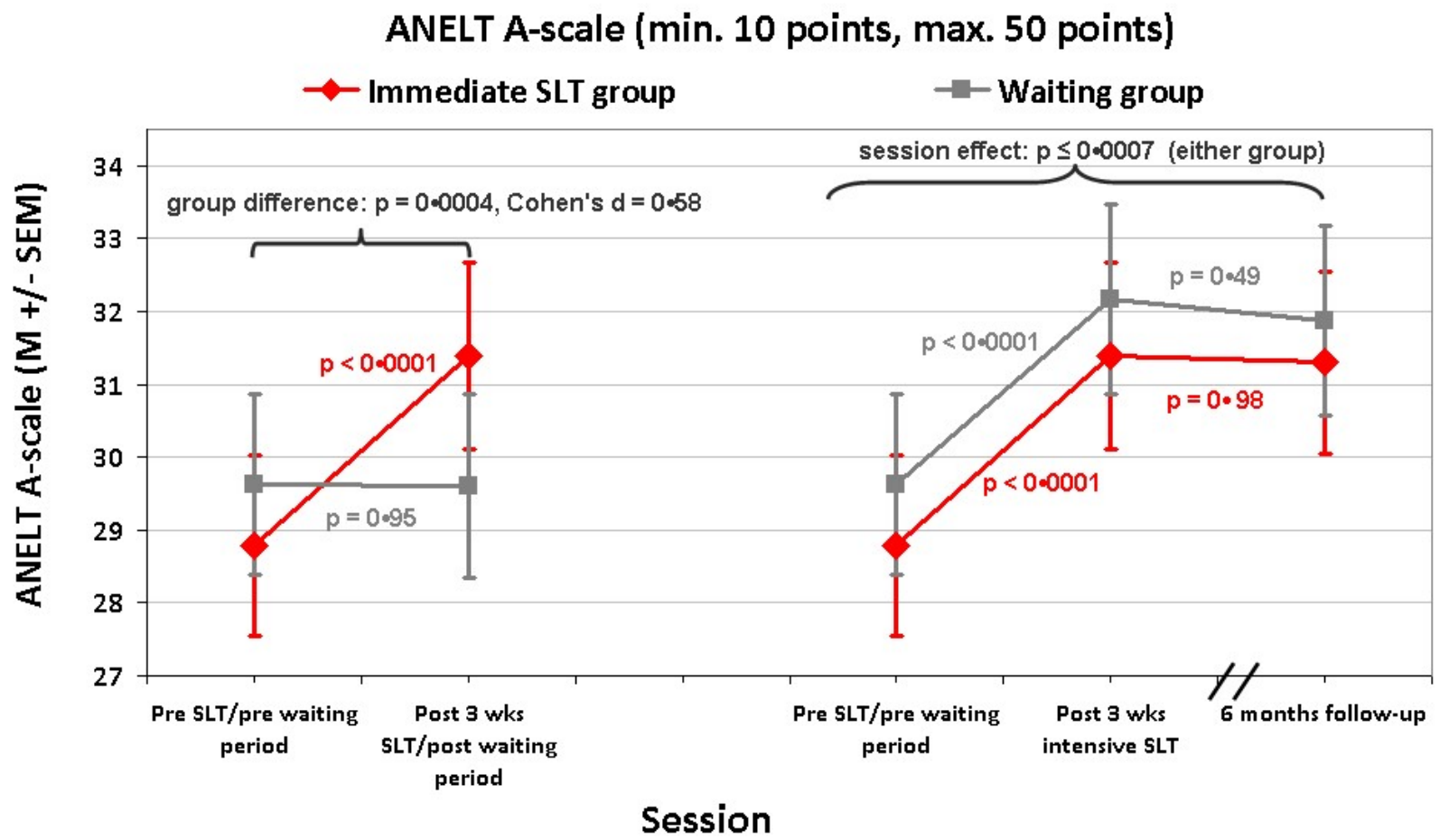

Figure 2: Left (primary endpoint): Mean +/- SEM ANELT A-scale score (minimum: 10 points; maximum: 50 points) from pre to post the 3-week intensive SLT (I-SLT-G: red line) versus 3-week waiting period (WL-CG: grey line). Right (secondary analyses without group factor): Mean +/- SEM ANELT A-scale score from pre (first baseline in the WL-CG) to post the 3-week intensive SLT and at the 6-month follow-up in the ISLT-G (red line) and the WL-CG (grey line). The effect size Cohen's d refers to the average group difference and standard deviation of differences from pre to post assessments. SLT = speech and language therapy. 


\section{$\underline{\text { Secondary analyses }}$}

\section{Primary outcome measure}

On the primary outcome measure (ANELT A-scale), the WL-CG showed no significant changes across the 3-week waiting period. Once the 3-week intensive SLT was delivered to this group, the gain in verbal communication was comparable to the ISLT-G (see Figure 2 - right panel and Suppl. Table 3). Both study groups showed stable treatment effects over the course of six months (see Figure 2 - right panel and Table 2).

An additional analysis for the subsample of patients with $\geq 5$ weeks of intensive SLT $(n=34)$ revealed that the treatment effect in the primary outcome measure (ANELT Ascale) after a median of six weeks of intensive SLT (mean increase from pre to post SLT: $4 \cdot 23$ +/- SEM 0.73 points; $95 \%$ CI: $2 \cdot 74$ to $5 \cdot 73$ ) was approximately one point larger compared to the assessment after the initial three weeks of intensive SLT (mean increase from pre to post SLT: 3.32 +/- SEM 0.97 points; 95\% CI: 1.35 to $5 \cdot 29$ ). Groups with intensive SLT limited to three weeks versus at least five weeks did not differ with respect to age, sex, years of education, initial stroke severity, aphasia severity, or aphasia syndrome distribution (all $\mathrm{p}>0 \cdot 13$ ).

\section{Secondary outcome measures}

Scores on the linguistic screening measure (SAPS; total score, as well as the lexicon and syntax subtotals; see Suppl. Information) and patients' health-related quality of life ratings (SAQOL-39: total score and subscale 'psychosocial') significantly improved from pre to post the 3 -week intensive SLT compared to the 3 -week waiting period (all p<0.05, see Table 2 and Fig. 3). Group differences in linguistic gains (SAPS scores) were not correlated with the analysed moderator variables (see Suppl. Information). 


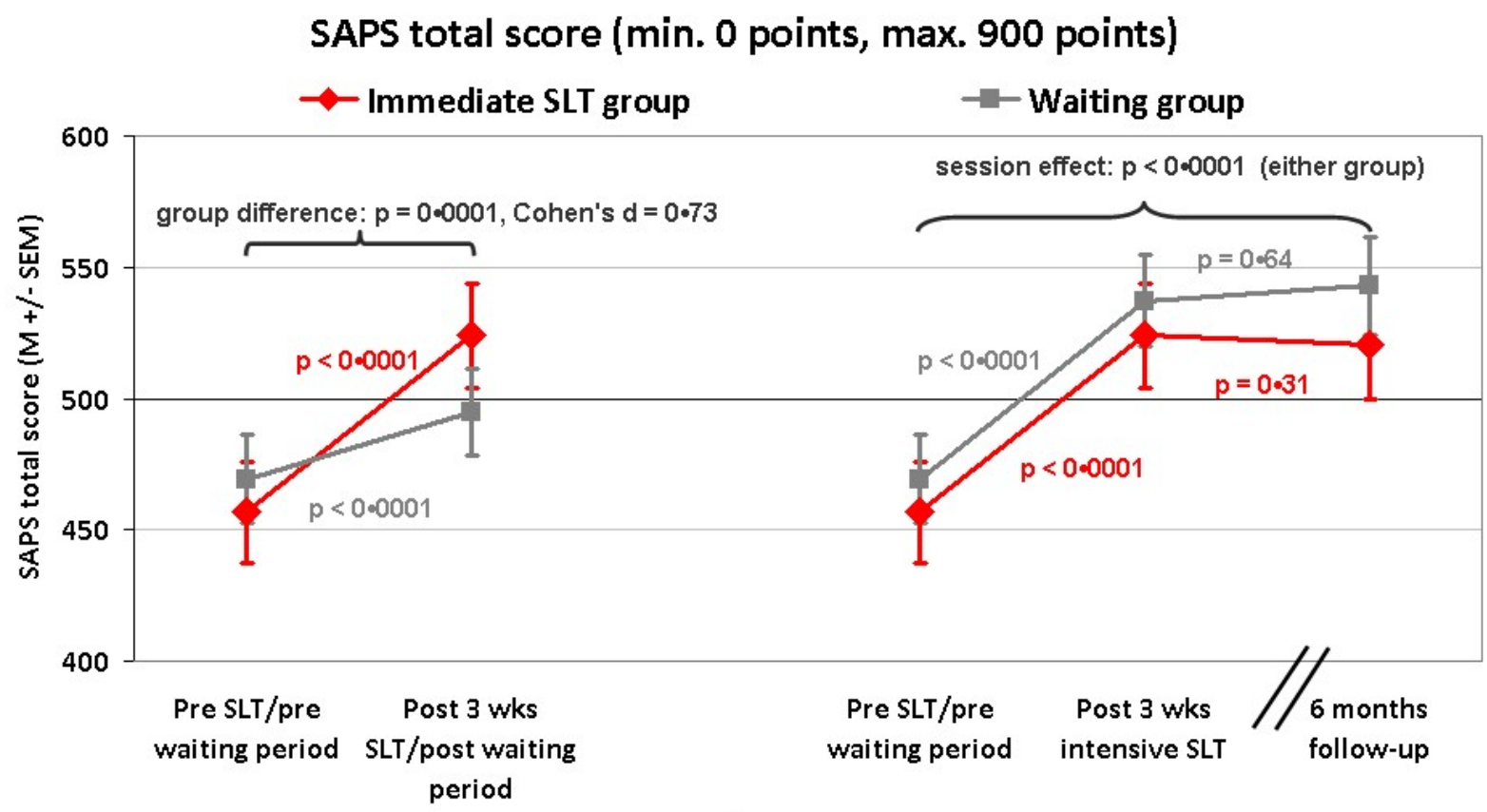

Session

Figure 3: Left: Mean +/- SEM score for the linguistic measure (SAPS total score) from pre to post the 3-week intensive SLT (I-SLT-G: red line) versus waiting (WL-CG: grey line). Right (analyses without group factor): Mean +/- SEM score on the SAPS total score from pre (first baseline in the WL-CG) to post the 3-week SLT and at the 6month follow-up in the I-SLT-G (red line) and the WL-CG (grey line). SLT = speech and language therapy.

Treatment-related gains on secondary outcomes, including significant others' judgements assessing the patients' communicative effectiveness (CETI) remained stable over the 6-month follow-up period in both groups (see Supp. Table 2).

No significant group differences from pre to post the 3-week intensive SLT versus waiting emerged for the ANELT B-scale (acoustic intelligibility), the SAPS phonology score, nonverbal cognitive functions (NVLT, TMTs), or stroke-related physical dependency (modified Rankin Scale/mRS).

\section{Predictors of primary treatment success}

Of all patient-, stroke- (see Suppl. Information), and SLT-related variables, only baseline stroke severity was a significant predictor of immediate treatment success in verbal communication. Patients with less severe stroke in the mRS at enrolment 
showed larger treatment gains. There were no significant predictors of long-term treatment stability over six months. 


\section{Discussion}

The results of the randomised multi-centre trial FCET2EC demonstrate that three weeks of intensive SLT administered under routine clinical conditions compared to three weeks deferral of intensive SLT significantly improved verbal communication (primary outcome) in patients with chronic post-stroke aphasia. Additionally, specific linguistic measures (lexicon, syntax) and communication-related quality of life ratings of both the patients and a significant other increased in response to intensive SLT. There were no significant moderators of the treatment effect, indicating that no particular feature of patient subgroups was driving the effect, and that therapy setting (in- or outpatient) did not influence the outcome. Untrained cognitive functions, like nonverbal learning or executive functioning, did not change from pre- to post-SLT, corroborating specificity of treatment effects.

Once treated with intensive SLT, the control group showed comparable improvements in primary and secondary language outcomes, thus replicating the primary treatment effect. Despite the chronic stage of their post-stroke aphasia, 69 of the 156 patients (44\%) improved by at least a mean difference of three points on the primary outcome measure from pre to post three weeks of intensive SLT, merely 16 patients (10\%) declined by at least three points. This indicates that the observed treatment effect is not based on a small group of outliers. Of note, the control group did not improve with an average of 1.5 hours of outpatient SLT/week during the 3-week waiting period and the entire intensively treated group did not improve with an average of $1 \cdot 2$ hours outpatient SLT/week during the 6-month follow-up period (see Supplementary Table 1 and Figure 2). Thus, even an extended period of low intensity SLT did not result in a significant treatment effect.

None of the randomised patients dropped out of the intensive SLT. Clearly, this mitigates the concern expressed by the most recent Cochrane review on aphasia rehabilitation (9) that superior outcomes of intensive versus non-intensive SLT studies may be biased by a higher drop-out rate in intensive SLT studies, resulting in a selection of particularly motivated patients. The absence of patient drop-outs during the intervention period also demonstrates the general feasibility of intensive SLT for routine clinical care. The problem of implementing intensive SLT into the clinical routine seems to be more of an economic nature as 153 patients could not participate 
in the intensive SLT intervention due to staff shortage in the respective rehabilitation centre at the time of the patient's referral.

The only significant predictor of primary treatment success was stroke severity. Stroke patients with milder stroke severity (mRS) at inclusion showed larger increases in verbal communication effectiveness from pre- to post-SLT. Furthermore, both study groups retained SL treatment gains over at least six months, demonstrating the stability of the effect.

The average gain of approximately three points on the primary outcome ANELT Ascale from pre- to post-intensive SLT may appear moderate with respect to the clinical impact. To our knowledge, there are no published studies on the association of ANELT change scores with clinical impact ratings. From a clinical perspective, even a 1-point increase in verbal effectiveness in daily life situations, like changing a doctor's appointment by phone, is clinically important because it may reflect a change from "no relation to communicative scenario at all" (score 1) to "minimum requirements of the communicative scenario are fulfilled" (score 2). A numerically small change may thus reflect a categorical shift from "no social participation at all" to "at least low grade of social participation".

A few trials using the ANELT A-scale as therapy outcome measure reported average gains of at least five points from pre to post the intervention period. However, these studies included patients in the (sub-)acute phase post stroke. This magnitude of change is thus not directly comparable to our chronic stroke sample because of the strong influence of spontaneous language recovery during the first six months post stroke. For example, the RATS-1 study (15) found an average gain of about five points on the ANELT A-scale when comparing verbal communication at the subacute phase ( $\sim 3$ months post stroke) with a second assessment seven months later ( $\sim 10$ months post onset). The RATS-2 study (19) reported therapy-induced ANELT A-scale change scores of 10 points from the acute (3 weeks post onset) to the postacute (three months post the initial stroke) phase; from the subacute to the chronic (six months post stroke onset) phase, the incremental improvement was on average two points. Patients in the present study were on average several years beyond their last stroke, had received only three weeks of intensive SLT before the immediate outcome assessment and still gained on average three points (which represents more than $50 \%$ of the intraindividual 
SD). Therapy duration may also be a critical issue with respect to treatment effects: the subsample of 34 patients in our study with $\geq 5$ weeks of intensive SLT had gained on average $>4$ points compared to the baseline assessment. This indicates that more prolonged intensive treatment durations or repeated periods of intensive SLT in the chronic stage post stroke may yield even stronger treatment effects, comparable to those observed in the spontaneous recovery phase early after stroke. Thus, our findings undermine the dogma that functional improvements cannot be achieved in the chronic stage post-stroke. The magnitude of the observed therapy effect (about 10 percent improvement from baseline) is comparable to the typical improvement observed after several-week physiotherapy programs in chronic post-stroke motor rehabilitation (29) and may reflect a physiological limit of training-induced functional recovery after a single training episode in the chronic post-stroke stage.

The off-line scoring of the primary outcome measure by an independent endpoint committee was fully blinded. However, we concede that the administration of the primary outcome measure was not blinded due to the health care character of the study. Assessors were comprehensively trained in ANELT assessment; however, they remained naïve with respect to ANELT scoring. The scenario instructions had to be read word-for-word to the patient, no verbal or nonverbal interactions with the patient were otherwise permitted during assessment. The endpoint committee had verified during scoring that assessors had strictly complied with the protocol in all cases.

The major strength of the current trial is the demonstrated statistically significant improvement with medium to large effect sizes in verbal communication and linguistic abilities with a parallel increase in communication-related quality of life ratings of both the patients and their significant others after merely three weeks of intensive SLT, provided under routine clinical conditions, in a large sample of chronic post-stroke aphasia patients. Low intensity SLT as provided during the waiting period in the control group (mean of 1.5 hours/week) or during the 6-month follow-up period post intensive SLT (mean of $\mathbf{1 . 2}$ hours/week) was ineffective. We cannot rule out, however, that low intensity SLT may have supported the maintenance of the immediate treatment effect. This finding clearly demonstrates that a boost of intensive SLT is the key to successful aphasia rehabilitation in the chronic stage post stroke, urgently requiring a change in the way rehabilitation resources are currently used. 
We would like to acknowledge several limitations: The study design did not address whether there is a critical time window post-stroke to achieve maximum treatment effects. Patients were at least 6-month post the initial stroke in the present study (to methodologically control for the effects of spontaneous recovery), and the majority of patients were several years post-stroke (s. Table 1). A seminal study by Wertz and colleagues (30) had provided first evidence that intensive SLT is also effective when initiated in the (sub-) acute stage post-stroke. Furthermore, our findings cannot elucidate whether (i) a moderately less intense SLT regimen, e.g. six hours/week (13), is sufficient to achieve comparable effects, (ii) cumulative treatment effects can be achieved with extended treatment periods or repeated intensive SLT periods, (iii) patients aged $>70$ years or in the postacute post-stroke stage benefit similarly from intensive SLT as suggested by a recent cohort analysis (31), (iv) the observed treatment effect is specific to the agreed-best-practice SLT approach applied in the current study, (v) total hours of SLT provided are as important as treatment intensity (10), and (vi) low intensity SLT is required to achieve stability of treatment effects following the intensive intervention.

In conclusion, FCET2EC is the first multi-centre RCT in chronic post-stroke aphasia to directly demonstrate the superiority of intensive SLT to a no or low intensity treatment (waiting list) control condition. Three weeks of intensive SLT with $\geq 10$ hours/week in an in- or outpatient setting can thus be considered an evidence-based intervention for the entire population of stroke patients suffering from chronic aphasia.

\section{Contributors}

$\mathrm{AB}, \mathrm{CB}, \mathrm{AF}, \mathrm{WZ}$, TG, LS, and PM devised the study protocol. PM, WH, KW, EBR, and KGH were members of the FCET2EC Trial Steering Committee; EBR was the chairman. TG, SA, FD, RG, FR, KJS, MT, LS, and AB developed the intensive SLT treatment manual. RR, FW, IH, HO, EdL, CR, and JL participated in data collection and processing. $\mathrm{PM}, \mathrm{CB}, \mathrm{AB}, \mathrm{KW}, \mathrm{WH}, \mathrm{EBR}$, and $\mathrm{KGH}$ contributed to data analysis and interpretation. $\mathrm{CB}$ wrote the first draft of the manuscript with input from $\mathrm{AB}$ and $\mathrm{PM}$; $\mathrm{AF}, \mathrm{WZ}, \mathrm{TG}, \mathrm{WH}, \mathrm{KW}, \mathrm{EBR}, \mathrm{KGH}, \mathrm{HO}, \mathrm{SA}$ and FD edited the report. All authors were FCET2EC study collaborators and approved the final version of the manuscript. 


\section{$\underline{\text { Declaration of interests }}$}

We declare no competing interests.

Acknowledgements (further acknowledgements in Supplemental Information)

This investigator-initiated trial was funded by the German Ministry of Education and Research (BMBF, identifier: 01GY1144) and the German Society for Aphasia Research and Treatment (GAB). 


\section{Reference List}

1. Dijkerman HC, Wood VA, Hewer RL. Long-term outcome after discharge from a stroke rehabilitation unit. J R Coll Physicians Lond 1996;30(6):538-46.

2. Hilari K. The impact of stroke: are people with aphasia different to those without? Disabil Rehabil 2011;33(3):211-8.

3. Pollock A, St George B, Fenton M, Firkins L. Top ten research priorities relating to life after stroke. Lancet Neurol 2012;11(3):209.

Internet link: http://www.jla.nihr.ac.uk/priority-setting-partnerships/strokein-scotland/top-10-priorities/

4. Dickey L, Kagan A, Lindsay MP, Fang J, Rowland A, Black S. Incidence and profile of inpatient stroke-induced aphasia in Ontario, Canada. Arch Phys Med Rehabil 2010;91(2):196-202.

5. Doucet T, Muller F, Verdun-Esquer C, Debelleix X, Brochard P. Returning to work after a stroke: a retrospective study at the Physical and Rehabilitation Medicine Center La Tour de Gassies. Ann Phys Rehabil Med 2012;55(2):112-27.

6. Fisher A, Martin J, Srikusalanukul W, Davis M. Trends in stroke survival incidence rates in older Australians in the new millennium and forecasts into the future. J Stroke Cerebrovasc Dis 2014;23(4):759-70.

7. Ellis C, Simpson AN, Bonilha H, Mauldin PD, Simpson KN. The one-year attributable cost of poststroke aphasia. Stroke 2012;43(5):1429-31.

8. Cherney LR, Patterson JP, Raymer AM. Intensity of aphasia therapy: evidence and efficacy. Curr Neurol Neurosci Rep. 2011;11(6):560-9.

9. Brady MC, Kelly H, Godwin J, Enderby P, Campbell P. Speech and language therapy for aphasia following stroke. Cochrane Database Syst Rev 2016;6:CDoo0425.

10. Bhogal SK, Teasell R, Speechley M. Intensity of aphasia therapy, impact on recovery. Stroke 2003;34(4):987-93.

11. Allen L, Mehta S, McClure JA, Teasell R. Therapeutic interventions for aphasia initiated more than six months post stroke: a review of the evidence. Top Stroke Rehabil 2012;19(6):523-35.

12. Robey RR. A meta-analysis of clinical outcomes in the treatment of aphasia. $\mathrm{J}$ Speech Lang Hear Res 1998;41(1):172-87.

13. Dignam J, Copland D, McKinnon E, Burfein P, O'Brien K, Farrell A et al. Intensive Versus Distributed Aphasia Therapy: A Nonrandomized, ParallelGroup, Dosage-Controlled Study. Stroke 2015;46(8):2206-11. 
14. Pulvermüller F, Neininger B, Elbert T, Mohr B, Rockstroh B, Koebbel P et al. Constraint-induced therapy of chronic aphasia after stroke. Stroke 2001;32(7):1621-6.

15. Doesborgh SJ, van de Sandt-Koenderman MW, Dippel DW, van Harskamp F, Koudstaal PJ, Visch-Brink EG. Effects of semantic treatment on verbal communication and linguistic processing in aphasia after stroke: a randomized controlled trial. Stroke 2004;35(1):141-6.

16. Meinzer M, Djundja D, Barthel G, Elbert T, Rockstroh B. Long-term stability of improved language functions in chronic aphasia after constraint-induced aphasia therapy. Stroke 2005;36(7):1462-6.

17. Bowen A, Hesketh A, Patchick E, Young A, Davies L, Vail A et al. Effectiveness of enhanced communication therapy in the first four months after stroke for aphasia and dysarthria: a randomised controlled trial. BMJ 2012;345:e4407.

18. Laska AC, Kahan T, Hellblom A, Murray V, Von Arbin M. A randomized controlled trial on very early speech and language therapy in acute stroke patients with aphasia. Cerebrovasc.Dis.Extra. 2011;1(1):66-74.

19. Jong-Hagelstein M, van de Sandt-Koenderman WM, Prins ND, Dippel DW, Koudstaal PJ, Visch-Brink EG. Efficacy of early cognitive-linguistic treatment and communicative treatment in aphasia after stroke: a randomised controlled trial (RATS-2). J Neurol Neurosurg Psychiatry 2011;82(4):399-404.

20. Bakheit AM, Shaw S, Barrett L, Wood J, Carrington S, Griffiths S et al. A prospective, randomized, parallel group, controlled study of the effect of intensity of speech and language therapy on early recovery from poststroke aphasia. Clin Rehabil 2007;21(10):885-94.

21. Baumgaertner A, Grewe T, Ziegler W, Floel A, Springer L, Martus P et al. FCET2EC (From controlled experimental trial to $=2$ everyday communication): How effective is intensive integrative therapy for stroke-induced chronic aphasia under routine clinical conditions? A study protocol for a randomized controlled trial. Trials 2013;14:308.

22. Huber W, Poeck K, Willmes K. The Aachen Aphasia Test. Adv Neurol 1984;42:291-303.

23. Blomert L, Kean ML, Koster C, Schokker J. Amsterdam Nijmegen Everyday Language Test: construction, reliability and validity. Aphasiology 1994;8:381407 .

24. van Swieten JC, Koudstaal PJ, Visser MC, Schouten HJ, van Gijn J. Interobserver agreement for the assessment of handicap in stroke patients. Stroke 1988;19(5):604-7.

25. Hilari K, Byng S, Lamping DL, Smith SC. Stroke and Aphasia Quality of Life Scale-39 (SAQOL-39): evaluation of acceptability, reliability, and validity. Stroke 2003;34(8):1944-50. 
26. Lomas J, Pickard L, Bester S, Elbard H, Finlayson A, Zoghaib C. The communicative effectiveness index: development and psychometric evaluation of a functional communication measure for adult aphasia. J Speech Hear Disord 1989;54(1):113-24.

27. Sturm W, Willmes K. Verbaler und Nonverbaler Lerntest. Göttingen: Hogrefe; 1999.

28. Bowie CR, Harvey PD. Administration and interpretation of the Trail Making Test. Nat Protoc. 2006;1(5):2277-81.

29. Ramos-Murguialday A, Broetz D, Rea M, Laer L, Yilmaz O, Brasil FL et al. Brain-machine interface in chronic stroke rehabilitation: a controlled study. Ann Neurol 2013;74(1):100-8.

30. Wertz RT, Weiss DG, Aten JL, Brookshire RH, Garcia-Bunuel L, Holland AL et al. Comparison of clinic, home, and deferred language treatment for aphasia. A Veterans Administration Cooperative Study. Arch Neurol 1986;43(7):653-8.

31. Knecht S, Rossmuller J, Unrath M, Stephan KM, Berger K, Studer B. Old benefit as much as young patients with stroke from high-intensity neurorehabilitation: cohort analysis. J Neurol Neurosurg Psychiatry 2016;87(5):526-30. 
Table 1: Basic baseline characteristics and therapy data

\begin{tabular}{|c|c|c|c|}
\hline Variable & & Immediate SLT group & Control group \\
\hline & & $(n=78)$ & $(n=78)$ \\
\hline \multicolumn{4}{|l|}{ Basic baseline characteristics } \\
\hline \multicolumn{4}{|l|}{ Demographics } \\
\hline Age in years $(\mathrm{M}+/-\mathrm{SD}$, range $)$ & & $53 \cdot 49+/-9 \cdot 02,29-69$ & $52 \cdot 88+/-10 \cdot 18,23-70$ \\
\hline sex (n: female/male) & & $32 / 46(41 \% / 59 \%)$ & $24 / 54(31 \% / 69 \%)$ \\
\hline Education years (median; min.-max.; Q1-Q3) & & $10 ; 8-19 ; 10-19$ & $10 ; 8-19 ; 10-16 \cdot 5$ \\
\hline \multicolumn{4}{|l|}{ Stroke } \\
\hline $\begin{array}{l}\text { Current stroke severity - mRS, Range: o-6 } \\
\text { (median; min.-max.; Q1-Q3) }\end{array}$ & & $2 ; 1-4 ; 2-3$ & $2 ; 1-4 ; 2-3$ \\
\hline $\begin{array}{l}\text { Months post index stroke } \\
\text { (median; min.-max.; Q1-Q3) }\end{array}$ & & $43 ; 6-221 ; 16-68 \cdot 25$ & $27 ; 6-235 ; 13-48 \cdot 75$ \\
\hline \multirow{4}{*}{ Stroke subtype (n) } & ischemic & $45(58 \%)$ & $56(72 \%)$ \\
\hline & $\begin{array}{l}\text { ischemic with hemorrhagic } \\
\text { transformation }\end{array}$ & $19(24 \%)$ & $11(14 \%)$ \\
\hline & hemorrhagic & $9(12 \%)$ & $8(10 \%)$ \\
\hline & subarachnoid hemmorhage & $5(6 \%)$ & $3(4 \%)$ \\
\hline \multicolumn{4}{|l|}{ Stroke risk factors } \\
\hline Prior stroke/transient ischemic attack (n) & with/without prior aphasia & $2 / 7(3 \% / 9 \%)$ & $7 / 3(9 \% / 4 \%)$ \\
\hline Hypertension (n) & & $50(64 \%)$ & $57(73 \%)$ \\
\hline Hyperlipidemia (n) & & $37(47 \%)$ & $25(32 \%)$ \\
\hline \multirow{4}{*}{ Heart disease } & Atrial fibrillation (n) & $8(10 \%)$ & $7(9 \%)$ \\
\hline & Congestive heart failure (n) & $6(8 \%)$ & $4(5 \%)$ \\
\hline & History of myocardial infarction(n) & $11(14 \%)$ & $9(12 \%)$ \\
\hline & Coronary heart disease (n) & $12(15 \%)$ & $9(12 \%)$ \\
\hline Diabetes mellitus, type 2 (n) & & $6(8 \%)$ & $7(9 \%)$ \\
\hline Peripheral artery occlusive disease (n) & & $3(4 \%)$ & $\mathrm{O}$ \\
\hline No medical stroke risk factors (n) & & $17(22 \%)$ & $15(19 \%)$ \\
\hline \multicolumn{4}{|l|}{ Epilepsy/Depression } \\
\hline Antiepileptic medication (n) & & $38(49 \%)$ & $34(44 \%)$ \\
\hline Antidepressant medication (n) & & $24(31 \%)$ & $23(29 \%)$ \\
\hline Baseline depression score & & $2 \cdot 21+/-2 \cdot 77$ & $2 \cdot 60+/-2 \cdot .89$ \\
\hline
\end{tabular}




\begin{tabular}{|c|c|c|c|}
\hline Variable & & Immediate SLT group & Control group \\
\hline \multicolumn{4}{|l|}{ (VAMS sadness score, range: $0-10)(\mathrm{M}+/-\mathrm{SD})$} \\
\hline \multicolumn{4}{|c|}{$(n=78)$} \\
\hline \multicolumn{4}{|l|}{ Aphasia } \\
\hline \multirow{5}{*}{ Syndrome } & Global (n) & $20(26 \%)$ & $13(17 \%)$ \\
\hline & Wernicke (n) & $11(14 \%)$ & $14(18 \%)$ \\
\hline & Broca (n) & $22(28 \%)$ & $25(31 \%)$ \\
\hline & Anomic (n) & $18(23 \%)$ & $20(26 \%)$ \\
\hline & Not classifiable (n) & $7(9 \%)$ & $6(8 \%)$ \\
\hline Aphasia severity: AAT profile height & T-score (M +/-SD) & $50 \cdot 9+/-6 \cdot 6$ & $52 \cdot 3+/-5 \cdot 4$ \\
\hline \multirow{4}{*}{ Aphasia severity: classification * } & Minimal aphasia (n) & $3(4 \%)$ & $3(4 \%)$ \\
\hline & Mild aphasia (n) & $30(38 \%)$ & $34(44 \%)$ \\
\hline & Medium severe aphasia (n) & $38(49 \%)$ & $41(53 \%)$ \\
\hline & Severe aphasia (n) & $7(9 \%)$ & $\mathrm{O}$ \\
\hline \multicolumn{4}{|l|}{ Basic therapy data } \\
\hline $\begin{array}{l}\text { Total rehab duration in weeks } \\
\text { (median; min.-max.; Q1-Q3)) }\end{array}$ & & $4 \cdot 8 ; 3-10 ; 3-5 \cdot 6$ & $4 ; 3-9 ; 3-5$ \\
\hline \multirow{3}{*}{$\begin{array}{l}\text { SLT treatment hours in weeks 1-3 } \\
\text { (median; min.-max.; Q1-Q3) }\end{array}$} & total with SL therapist, of which: & $31 ; 22 \cdot 5-49 ; 30-34 \cdot 5$ & $32 ; 23-41 ; 30-34 \cdot 6$ \\
\hline & one-to-one & $22 ; 15 \cdot 5-35 \cdot 9 ; 21-24 \cdot 2$ & $22 \cdot 3 ; 17 \cdot 7-35 \cdot 3 ; 21-24$ \\
\hline & group sessions & $9 ; 2-16 ; 8-10 \cdot 5$ & $9 ; 0-15 \cdot 5 ; 8-10 \cdot 5$ \\
\hline $\begin{array}{l}\text { Hours of self-managed language exercises in } \\
\text { weeks 1-3 (median; min.-max.; Q1-Q3) }\end{array}$ & & $15 ; 0-18 ; 15-15$ & $15 ; 12-23 ; 15-15 \cdot 3$ \\
\hline \multirow{3}{*}{$\begin{array}{l}\text { Non-SLT treatment hours in weeks 1-3 } \\
\text { (median; min.-max.; Q1-Q3) }\end{array}$} & physiotherapy & $8 \cdot 8 ; 0-21 \cdot 3 ; 3-12 \cdot 5$ & $8 \cdot 5 ; 0-22 \cdot 5 ; 3 \cdot 8-11 \cdot 6$ \\
\hline & occupational therapy & $4 ; 0-20 ; 0-8$ & $6 ; 0-27 ; 2-9 \cdot 8$ \\
\hline & cognitive therapy & $0 ; 0-10 ; 0-0 \cdot 5$ & $0 ; 0-7 ; 0-0$ \\
\hline
\end{tabular}

M = mean; SD = standard deviation; mRS = modified Rankin Scale; Q1 = first quartile, Q3 = third quartile; VAMS = Visual analog mood scales; AAT = Aachen Aphasie Test; AAT profile height = average weighted T-scores of the AAT subtests; SLT = Speech and language therapy

Participants with global aphasia (and to a lesser degree with Wernicke's aphasia) do not show overall floor performance on the AAT because of the chronic stage post-stroke and because of our inclusion criteria [section on "Participants": “...basic comprehension abilities and at least rudimentary attempts to verbally communicate (communication score $>0$ on the AAT spontaneous speech rating scales), and the ability to follow simple instructions ( $\geq 1$ correct response on the first 10 items of the AAT Token Test)], Moreover, the AAT profile level (measure of aphasia severity) only provides an estimate of the overall performance level in the AAT subtests and does not include information on the profile of spontaneous speech ratings, which on the other hand is highly relevant for the syndrome group assignment. Therefore, some non-coincidences between aphasia syndrome and aphasia severity categorization are to be expected. 
Table 2: Immediate primary and secondary treatment effects (comparison of pre to post 3 weeks of therapy/waiting in the 2 groups)

\begin{tabular}{|c|c|c|c|c|c|c|c|c|c|c|}
\hline & & \multicolumn{3}{|c|}{ Immediate SLT group } & \multicolumn{3}{|c|}{ Control group } & \multicolumn{3}{|c|}{ Group difference } \\
\hline & & $\begin{array}{c}\text { pre } 3 \text { weeks } \\
\text { SLT }\end{array}$ & $\begin{array}{c}\text { post } 3 \text { weeks } \\
\text { SLT }\end{array}$ & & $\begin{array}{c}\text { pre } 3 \text { weeks } \\
\text { waiting }\end{array}$ & $\begin{array}{c}\text { post } 3 \text { weeks } \\
\text { waiting }\end{array}$ & & \multicolumn{2}{|c|}{ ANCOVA } & \begin{tabular}{|c|}
$\begin{array}{c}\text { Effect } \\
\text { size }\end{array}$ \\
\end{tabular} \\
\hline & & $\mathrm{M}+/-\mathrm{SD}$ & $\mathrm{M}+/-\mathrm{SD}$ & $\begin{array}{l}\text { t-test } \\
(\mathrm{p}- \\
\text { value })\end{array}$ & $\mathrm{M}+/-\mathrm{SD}$ & $\mathrm{M}+/-\mathrm{SD}$ & $\begin{array}{l}\text { t-test } \\
(\mathrm{p}- \\
\text { value) }\end{array}$ & $F(d f 1, d f 2)$ & p-value & $\begin{array}{c}\text { Cohen's } \\
\text { d }\end{array}$ \\
\hline \multicolumn{11}{|c|}{ Primary outcome measure } \\
\hline $\begin{array}{l}\text { Verbal } \\
\text { communication - } \\
\text { ANELT A-scale }\end{array}$ & $\begin{array}{l}\text { Sum score } \\
\text { (range: } 10-50 \text { ) }\end{array}$ & $\begin{array}{c}28 \cdot 79+/- \\
10 \cdot 90(n=78) \\
\end{array}$ & $\begin{array}{c}31 \cdot 39+/- \\
11 \cdot 27(\mathrm{n}=78)\end{array}$ & $<0 \cdot 0001$ & $\begin{array}{c}29 \cdot 63+/- \\
10 \cdot 94(\mathrm{n}=78)\end{array}$ & $\begin{array}{c}29 \cdot 60+/- \\
11 \cdot 11(n=78)\end{array}$ & 0.95 & $\begin{array}{c}12 \cdot 97 \\
(1,153)\end{array}$ & $0 \cdot 0004$ & $0 \cdot 58$ \\
\hline
\end{tabular}

\section{Secondary outcome measures}

\section{Communication}

ANELT B-scale -

auditory

Sum score

(range: 10-50)

\begin{tabular}{|c|c|}
$\begin{array}{c}37 \cdot 46+/-8 \cdot 25 \\
(\mathrm{n}=77)\end{array}$ & $\begin{array}{c}38 \cdot 16+/-7 \cdot 58 \\
(\mathrm{n}=77)\end{array}$ \\
\hline
\end{tabular}

$(\mathrm{n}=77)$

$37 \cdot 61+/-6 \cdot 85 \quad 37 \cdot 67+/-7 \cdot 35$

$(\mathrm{n}=78)$

$(\mathrm{n}=78)$

0.87

$1 \cdot 12$

\begin{tabular}{l|l}
$(1,152)$ & $0 \cdot 29$ \\
\hline
\end{tabular}

$0 \cdot 17$

\begin{tabular}{|c|c|c|c|c|c|c|c|c|c|c|}
\hline \multicolumn{11}{|l|}{$\begin{array}{l}\text { Linguistic } \\
\text { performance }\end{array}$} \\
\hline \multirow{6}{*}{$\begin{array}{l}\text { Language } \\
\text { systematic } \\
\text { modules -SAPS }\end{array}$} & $\begin{array}{l}\text { Total score } \\
(\max .900)\end{array}$ & $\begin{array}{c}456 \cdot 76+/- \\
159 \cdot 74(\mathrm{n}=69)\end{array}$ & $\begin{array}{c}523 \cdot 89+/- \\
164 \cdot 29(\mathrm{n}=69)\end{array}$ & $<0 \cdot 0001$ & $\begin{array}{c}469 \cdot 32+/- \\
144 \cdot 33(n=72)\end{array}$ & $\begin{array}{c}494 \cdot 86+-/- \\
142 \cdot 15(\mathrm{n}=72)\end{array}$ & $<0 \cdot 0001$ & $\begin{array}{c}18 \cdot 73 \\
(1,138)\end{array}$ & $0 \cdot 0001$ & $0 \cdot 73$ \\
\hline & $\begin{array}{l}\text { Phonology } \\
\text { (max. 300) }\end{array}$ & $\begin{array}{c}164 \cdot 97+/- \\
62 \cdot 13(\mathrm{n}=75)\end{array}$ & $\begin{array}{c}182 \cdot 68+/- \\
64 \cdot 22(n=75)\end{array}$ & $<0 \cdot 0001$ & $\begin{array}{c}167 \cdot 84+/- \\
60 \cdot 97(n=76)\end{array}$ & $\begin{array}{c}179 \cdot 73+/- \\
58 \cdot 87(n=76)\end{array}$ & $<0 \cdot 0001$ & $\begin{array}{c}1 \cdot 89 \\
(1,148)\end{array}$ & $0 \cdot 17$ & $0 \cdot 23$ \\
\hline & $\begin{array}{l}\text { Lexicon } \\
(\max .300)\end{array}$ & $\begin{array}{c}186 \cdot 38+/- \\
68 \cdot 83(\mathrm{n}=77)\end{array}$ & $\begin{array}{c}202 \cdot 68+/- \\
61 \cdot .56(\mathrm{n}=78)\end{array}$ & $<0 \cdot 0001$ & $\begin{array}{c}193 \cdot 06+/- \\
53 \cdot 63(\mathrm{n}=78)\end{array}$ & $\begin{array}{c}199 \cdot 53+/- \\
54 \cdot 52(\mathrm{n}=78)\end{array}$ & $0 \cdot 0174$ & $\begin{array}{c}5 \cdot 30 \\
(1,152) \\
\end{array}$ & $0 \cdot 0227$ & $0 \cdot 38$ \\
\hline & $\begin{array}{l}\text { Syntax } \\
(\max .300)\end{array}$ & $\begin{array}{c}104 \cdot 33+/- \\
55 \cdot 74(\mathrm{n}=73)\end{array}$ & $\begin{array}{c}133 \cdot 20+/- \\
58 \cdot 97(\mathrm{n}=74)\end{array}$ & $<0 \cdot 0001$ & $\begin{array}{c}106 \cdot 40+/- \\
59 \cdot 00(\mathrm{n}=77) \\
\end{array}$ & $\begin{array}{c}112 \cdot 60+/- \\
59 \cdot 55(n=75)\end{array}$ & $0 \cdot 22$ & $\begin{array}{c}17 \cdot 24 \\
(1,141) \\
\end{array}$ & $0 \cdot 0001$ & 0.68 \\
\hline & $\begin{array}{l}\text { Language } \\
\text { comprehension } \\
(\max .324)\end{array}$ & $\begin{array}{c}182 \cdot 04+/- \\
61 \cdot 42(\mathrm{n}=71)\end{array}$ & $\begin{array}{c}213 \cdot 66+/- \\
53 \cdot 81(\mathrm{n}=71)\end{array}$ & $<0 \cdot 0001$ & $\begin{array}{c}189 \cdot 61+/- \\
53 \cdot 53(\mathrm{n}=75)\end{array}$ & $\begin{array}{c}199 \cdot 47+/- \\
51 \cdot 89(n=75)\end{array}$ & $0 \cdot 0002$ & $\begin{array}{c}18 \cdot 67 \\
(1,143)\end{array}$ & $0 \cdot 0001$ & $0 \cdot 71$ \\
\hline & $\begin{array}{l}\text { Language } \\
\text { production } \\
(\max .576)\end{array}$ & $\begin{array}{c}280 \cdot 33+/- \\
130 \cdot 14(n=76)\end{array}$ & $\begin{array}{c}317 \cdot 71+/- \\
143 \cdot 11(\mathrm{n}=75)\end{array}$ & $<0 \cdot 0001$ & $\begin{array}{c}287 \cdot 76+/- \\
117 \cdot 61(n=76)\end{array}$ & $\begin{array}{c}302 \cdot 91+/- \\
117 \cdot 91(\mathrm{n}=75)\end{array}$ & $0 \cdot 0010$ & $\begin{array}{c}8 \cdot 49 \\
(1,148)\end{array}$ & $0 \cdot 0041$ & 0.48 \\
\hline
\end{tabular}




\begin{tabular}{|c|c|c|c|c|c|c|c|c|c|c|}
\hline & & \multicolumn{2}{|c|}{ Immediate SLT group } & & \multicolumn{3}{|l|}{ Control group } & \multicolumn{3}{|c|}{ Group difference } \\
\hline & & \multirow{2}{*}{$\begin{array}{c}\text { pre } 3 \text { weeks } \\
\text { SLT } \\
\\
\\
\mathrm{M}+/-\mathrm{SD} \\
\end{array}$} & \multirow{2}{*}{$\begin{array}{c}\text { post } 3 \text { weeks } \\
\text { SLT } \\
\\
\mathrm{M}+/-\mathrm{SD} \\
\end{array}$} & \multirow[b]{2}{*}{$\begin{array}{c}\text { t-test } \\
(\mathrm{p}- \\
\text { value) }\end{array}$} & \multirow{2}{*}{$\begin{array}{c}\text { pre } 3 \text { weeks } \\
\text { waiting } \\
\\
\mathrm{M}+/-\mathrm{SD} \\
\end{array}$} & \multirow{2}{*}{$\begin{array}{l}\text { post } 3 \text { weeks } \\
\text { SLT } \\
\mathrm{M}+/-\mathrm{SD}\end{array}$} & \multirow[b]{2}{*}{$\begin{array}{l}\text { t-test } \\
(\mathrm{p}- \\
\text { value) } \\
\end{array}$} & \multicolumn{2}{|c|}{ ANCOVA } & \multirow{2}{*}{\begin{tabular}{|c|}
$\begin{array}{c}\text { Effect } \\
\text { size }\end{array}$ \\
$\begin{array}{c}\text { Cohen's } \\
\text { d }\end{array}$ \\
\end{tabular}} \\
\hline & & & & & & & & $\mathrm{F}(\mathrm{df} 1, \mathrm{df} 2)$ & p-value & \\
\hline \multicolumn{11}{|l|}{ Quality of life } \\
\hline \multicolumn{11}{|l|}{ Patient's view } \\
\hline \multirow{5}{*}{$\begin{array}{l}\text { SAQOL-39 } \\
\text { (item scores } \\
\text { ranging from 1-5) }\end{array}$} & $\begin{array}{l}\text { Mean total } \\
\text { score (39 } \\
\text { items) } \\
\end{array}$ & $\begin{array}{c}3 \cdot 67+/-0 \cdot 52 \\
(n=78)\end{array}$ & $\begin{array}{c}3 \cdot 90+/-0 \cdot 54 \\
(n=78)\end{array}$ & $<0 \cdot 0001$ & $\begin{array}{c}3 \cdot 58+/-0 \cdot 61 \\
(n=78)\end{array}$ & $\begin{array}{c}3 \cdot 69+/-0 \cdot 61 \\
(n=78)\end{array}$ & $0 \cdot 0216$ & $\begin{array}{c}4 \cdot 45 \\
(1,153)\end{array}$ & 0.0365 & $0 \cdot 27$ \\
\hline & \begin{tabular}{|l|} 
Mean physical \\
score (17 items) \\
\end{tabular} & $\begin{array}{c}4 \cdot 05+/-0 \cdot 65 \\
(n=78)\end{array}$ & $\begin{array}{c}4 \cdot 18+/-0 \cdot 64 \\
(n=78)\end{array}$ & $0 \cdot 0120$ & $\begin{array}{c}3 \cdot 88+/-0 \cdot 79 \\
(\mathrm{n}=78)\end{array}$ & $\begin{array}{c}3 \cdot 97+/-0 \cdot 75 \\
\quad(n=78)\end{array}$ & 0.06 & $\begin{array}{c}1 \cdot 24 \\
(1,153)\end{array}$ & $0 \cdot 27$ & $0 \cdot 08$ \\
\hline & $\begin{array}{l}\text { Mean } \\
\text { communication } \\
\text { score (7 items) }\end{array}$ & $\begin{array}{c}2 \cdot 78+/-0 \cdot 74 \\
(n=78)\end{array}$ & $\begin{array}{c}3 \cdot 15+/-0 \cdot 73 \\
(n=78)\end{array}$ & $<0 \cdot 0001$ & $\begin{array}{c}2 \cdot 66+/-0 \cdot 76 \\
(n=78)\end{array}$ & $\begin{array}{c}2 \cdot 90+/-0 \cdot 78 \\
(n=78)\end{array}$ & $0 \cdot 0011$ & $\begin{array}{c}3 \cdot 41 \\
(1,153)\end{array}$ & $0 \cdot 07$ & $0 \cdot 21$ \\
\hline & $\begin{array}{l}\text { Mean } \\
\text { psychosocial } \\
\text { score (11 items) }\end{array}$ & $\begin{array}{c}3 \cdot 64+/-0 \cdot 79 \\
(n=78)\end{array}$ & $\begin{array}{c}3 \cdot 90+/-0 \cdot 78 \\
(n=78)\end{array}$ & $0 \cdot 0003$ & $\begin{array}{c}\begin{array}{c}3 \cdot 63+/-0 \cdot 88 \\
(n=78)\end{array}\end{array}$ & $\begin{array}{c}3 \cdot 71+/-0 \cdot 79 \\
(\mathrm{n}=78)\end{array}$ & $0 \cdot 37$ & $\begin{array}{c}3 \cdot 86 \\
(1,153)\end{array}$ & $0 \cdot 0513$ & $0 \cdot 27$ \\
\hline & $\begin{array}{l}\text { Mean energy } \\
\text { score (4 items) }\end{array}$ & $\begin{array}{c}3 \cdot 72+/-0 \cdot 83 \\
(n=78)\end{array}$ & $\begin{array}{c}4 \cdot 01+/-0 \cdot 85 \\
(n=78)\end{array}$ & $0 \cdot 0012$ & $\begin{array}{c}3 \cdot 77+/-0 \cdot 94 \\
(n=78)\end{array}$ & $\begin{array}{c}3 \cdot 87+/-0 \cdot 90 \\
(n=78)\end{array}$ & $0 \cdot 23$ & $\begin{array}{c}2 \cdot 27 \\
(1,153)\end{array}$ & $0 \cdot 13$ & $0 \cdot 24$ \\
\hline \multicolumn{11}{|l|}{$\begin{array}{l}\text { Significant other's } \\
\text { view }\end{array}$} \\
\hline $\begin{array}{l}\text { CETI (not assessed } \\
\text { after 3-week SLT) }\end{array}$ & \begin{tabular}{|l|} 
Total score \\
(range: $16-160$ )
\end{tabular} & $\begin{array}{c}83 \cdot 61+/- \\
28 \cdot 15(n=76)\end{array}$ & $\mathrm{n} / \mathrm{a}$ & $\mathrm{n} / \mathrm{a}$ & $\begin{array}{c}83 \cdot 64+/- \\
25 \cdot 56(n=74)\end{array}$ & $\begin{array}{c}83 \cdot 05+/- \\
28 \cdot 84(\mathrm{n}=74)\end{array}$ & $0 \cdot 76$ & $\mathrm{n} / \mathrm{a}$ & $\mathrm{n} / \mathrm{a}$ & $\mathrm{n} / \mathrm{a}$ \\
\hline
\end{tabular}




\begin{tabular}{|c|c|c|c|c|c|c|c|c|c|c|}
\hline & & \multicolumn{3}{|c|}{ Immediate SLT group } & \multicolumn{3}{|c|}{ Control group } & \multicolumn{3}{|c|}{ Group difference } \\
\hline & & \multirow{2}{*}{$\begin{array}{c}\text { pre } 3 \text { weeks } \\
\text { SLT } \\
\\
M+/-S D \\
\end{array}$} & \multirow{2}{*}{$\begin{array}{c}\text { post } 3 \text { weeks } \\
\text { SLT } \\
\\
\\
M+/- \text { SD } \\
\end{array}$} & \multirow[b]{2}{*}{$\begin{array}{c}\text { t-test } \\
\text { (p- } \\
\text { value) }\end{array}$} & \multirow{2}{*}{$\begin{array}{c}\text { pre } 3 \text { weeks } \\
\text { waiting } \\
\\
\mathrm{M}+/-\mathrm{SD} \\
\end{array}$} & \multirow{2}{*}{$\begin{array}{l}\text { post } 3 \text { weeks } \\
\text { SLT } \\
\\
M+/- \text { SD } \\
\end{array}$} & \multirow[b]{2}{*}{$\begin{array}{l}\text { t-test } \\
(\mathrm{p}- \\
\text { value) } \\
\end{array}$} & \multicolumn{2}{|c|}{ ANCOVA } & \multirow{2}{*}{$\begin{array}{c}\begin{array}{c}\text { Effect } \\
\text { size }\end{array} \\
\begin{array}{c}\text { Cohen's } \\
\text { d }\end{array} \\
\end{array}$} \\
\hline & & & & & & & & $\mathrm{F}(\mathrm{df} 1, \mathrm{df} 2)$ & $\begin{array}{c}\mathrm{p}- \\
\text { value }\end{array}$ & \\
\hline \multicolumn{11}{|l|}{$\begin{array}{l}\text { Nonverbal } \\
\text { cognitive } \\
\text { functioning }\end{array}$} \\
\hline NVLT & $\begin{array}{l}\text { Hits minus } \\
\text { false alarms }\end{array}$ & $\begin{array}{c}17 \cdot 17+/-8 \cdot 60 \\
(\mathrm{n}=72)\end{array}$ & $\begin{array}{c}19 \cdot 89+/- \\
8 \cdot 84(\mathrm{n}=72)\end{array}$ & $0 \cdot 0019$ & $\begin{array}{c}13 \cdot 53+/-9 \cdot 26 \\
(\mathrm{n}=76)\end{array}$ & $\begin{array}{c}16 \cdot 43+/- \\
11 \cdot 29(\mathrm{n}=76)\end{array}$ & $0 \cdot 0002$ & $\begin{array}{c}0 \cdot 84 \\
(1,145)\end{array}$ & $0 \cdot 77$ & $-0 \cdot 03$ \\
\hline & & & & & & & & & & \\
\hline \multirow{2}{*}{$\begin{array}{l}\text { TMT - sec until } \\
\text { completion }\end{array}$} & $\begin{array}{l}\text { version A } \\
\text { (max. 18o sec) }\end{array}$ & $\begin{array}{c}73 \cdot 34+/- \\
39 \cdot 53(\mathrm{n}=65) \\
\end{array}$ & $\begin{array}{c}61 \cdot 45+/- \\
29 \cdot 61(\mathrm{n}=65)\end{array}$ & $0 \cdot 0001$ & \begin{tabular}{|c|}
$76 \cdot 54+/-$ \\
$35 \cdot 20(\mathrm{n}=70)$ \\
\end{tabular} & $\begin{array}{c}63 \cdot 77+/- \\
25 \cdot 58(\mathrm{n}=7 \mathrm{o}) \\
\end{array}$ & $0 \cdot 0001$ & $\begin{array}{c}0 \cdot 03 \\
(1,132)\end{array}$ & $0 \cdot 86$ & $0 \cdot 04$ \\
\hline & $\begin{array}{l}\text { version B } \\
\text { (max. 300 sec) }\end{array}$ & $\begin{array}{c}176 \cdot 03+/- \\
56 \cdot 63(\mathrm{n}=34)\end{array}$ & $\begin{array}{c}162 \cdot 74+/- \\
56 \cdot 33(\mathrm{n}=34)\end{array}$ & $0 \cdot 14$ & $\begin{array}{c}175 \cdot 43+/- \\
54 \cdot 00(\mathrm{n}=30)\end{array}$ & $\begin{array}{c}153 \cdot 03+/- \\
55 \cdot 16(\mathrm{n}=30)\end{array}$ & $0 \cdot 0006$ & $\begin{array}{c}0 \cdot 84 \\
(1,61)\end{array}$ & $0 \cdot 36$ & $0 \cdot 21$ \\
\hline \multicolumn{11}{|l|}{ Stroke severity } \\
\hline $\begin{array}{l}\text { modified Rankin } \\
\text { Scale }\end{array}$ & $\begin{array}{l}\text { score } \\
\text { (range: o-6) }\end{array}$ & $\begin{array}{c}2 \cdot 21+/-0 \cdot 80 \\
(n=78)\end{array}$ & $\begin{array}{c}2 \cdot 21+/-0 \cdot 83 \\
(\mathrm{n}=78)\end{array}$ & 0.99 & $\begin{array}{c}2 \cdot 41+/-0 \cdot 96 \\
(\mathrm{n}=78)\end{array}$ & $\begin{array}{c}2 \cdot 33+/-0 \cdot 85 \\
(\mathrm{n}=78)\end{array}$ & & $\begin{array}{c}0 \cdot 19 \\
(1,153)\end{array}$ & $0 \cdot 6$ & \\
\hline
\end{tabular}

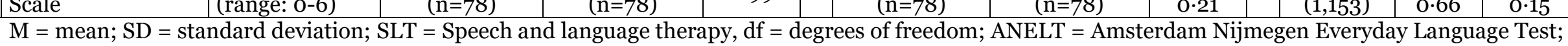
SAPS = Sprachsystematisches Aphasiescreening [langugage-systematic aphasia screening]; SAQOL-39 = Stroke and Aphasia Quality of Life Scale-39; CETI = Communicative Effectiveness Index; NVLT = Nonverbal Learning Test; TMT = Trail Making Test; $\mathrm{n} / \mathrm{a}=$ not applicable.

The effect size Cohen's d refers to the average group difference (and standard deviations) of the differences from pre to post assessments. The sign "-" has been chosen when the result was in favour of the waiting group, regardless of scale orientation. 
Intensive SLT improves verbal communication in chronic post-stroke aphasia FCET2EC Supplemental Information

\section{FCET2EC screening measures, candidate predictor and moderator variables, and details on the therapy regimen and treatment per-protocol}

$\underline{\text { Screening measures and secondary outcome measures }}$

In an initial screening session prior to study inclusion, the following measures were administered:

- language: Aachen Aphasia Test/AAT (1), comprising an assessment of spontaneous speech (study inclusion criterion: communication score $>0$ ), the Token Test, written language, repetition, naming, and language comprehension. AAT results were used to determine aphasia syndrome (Broca, Wernicke, global, anomic, non-classifiable) and severity [average weighted score of all AAT subtests: AAT profile-level T-score; the AAT profile level T-score also served to classify patients into aphasia severity groups: severe (T-score $<46)$, moderate (T-score: 46-54.9), mild (T-score: 55-62.9; minimal (T-score > 63)],

- apraxia of speech: 48-item version of the Hierarchical Word Lists (HWL) (2),

- visual neglect: Bells Test (3),

- nonverbal intellectual functioning: Subtest picture completion of the Wechsler Adult Intelligence Scale - Revised (WAIS-R) (4),

- verbal and nonverbal attention/working memory: Subtests digit span and visual span of the Wechsler Memory Scale - Revised (WMS-R) (5),

- nonverbal short-term memory: Benton Visual Retention Test (BVRT) (6),

- retrospective assessment of premorbid handedness (Edinburgh Handedness Inventory (EHI) (7),

- depressive mood assessed with the "sadness" item of the Visual Analog Mood Scales (VAMS) (8). 
Intensive SLT improves verbal communication in chronic post-stroke aphasia

$\underline{\text { Candidate predictor variables of the immediate and the long-term treatment success }}$ for the primary outcome ANELT A-scale

To determine potential predictors of the immediate and long-term primary outcome, respectively, the contribution of the following patient-, stroke-, aphasia-, and treatment-related variables was examined:

Sex, age, years of education, treatment center, therapy setting (in- vs. outpatient), baseline stroke severity (mRS), number of prior strokes, months post index stroke onset, thrombolysis (index stroke), hemicraniectomy, stroke type, TOAST classification, antiepileptic medication, antidepressive medication, baseline depression score (VAMS: sadness item), apraxia of speech, aphasia syndrome, aphasia severity, days of speech and language therapy (SLT) in weeks 1 to 3 , days with $\geq 60$ min SLT in weeks 1 to 3 , total hours of therapy-guided SLT in weeks 1 to 3 (one-to-one plus group sessions), hours of one-to-one SLT sessions in weeks 1 to 3 , hours of SLT group sessions in weeks 1 to 3 , ratio of one-to-one and group sessions in weeks 1 to 3 , hours of self-managed language exercises in weeks 1 to 3 , days of therapy interruption in weeks 1 to 3 , total hours of physical+occupational+cognitive therapies in weeks 1 to 3 , hours of physical therapy in weeks 1 to 3 , hours of occupational therapy in weeks 1 to 3 , hours of cognitive training in weeks 1 to 3 , entire SLT duration in weeks, total number of days with $\geq 60$ min SLT, total hours of therapy-guided SLT (one-to-one plus group sessions), total hours of one-to-one SLT sessions, total hours of group SLT sessions, total hours of self-managed language exercises, total days of therapy interruption, total hours of physical+occupational+

cognitive therapies, total hours of physical therapy, total hours of occupational therapy, total hours of cognitive training, total hours of SLT after study intervention up to 6months follow up.

\section{Candidate moderator variables}

The following variables were used to examine moderator effects on the immediate treatment effect (comparing the immediate SLT group to the control group from pre to post 3 weeks of SLT versus pre to post 3 weeks of waiting) for the primary outcome ANELT A-scale:

Sex, age, years of education, treatment center, therapy setting (in- or outpatient), stroke severity (modified Rankin Scale), number of prior strokes, months post index stroke, thrombolysis (index stroke), hemicraniectomy, stroke type, TOAST 
Intensive SLT improves verbal communication in chronic post-stroke aphasia classification, baseline depression score (Visual Analog Mood Scales/VAMS: sadness item), antidepressive medication, antiepileptic medication, apraxia of speech, aphasia syndrome, aphasia severity, nonverbal intellectual functioning (WAIS-R: picture completion), nonverbal short-term memory (BVRT), attention spans (WMS-R: verbal and visual spans), nonverbal learning ability (Nonverbal Learning Test/NVLT), working memory (Trail Making Test/TMT: versions A and B).

Treatment duration, dosage, intensity, and content

Treatment was administered to all participating patients for a duration of at least three weeks (15 consecutive treatment days, excluding weekends and public holidays). During this intervention, patients received manual-based, yet individually tailored therapist-guided SLT for at least one hour per day, totalling at least 10 hours per week (treatment intensity). About two thirds of the therapy targeted language-systematic and about one third communicative-pragmatic language functions (therapy content) (9-11). Therapy was administered in one-to-one (two thirds of total therapy time) as well as in group therapy settings (one third of total therapy time). Patients additionally performed self-managed linguistically based exercises (if suitable with a standardized PC training program) customized to their individual therapy foci for at least one hour per day, totalling at least five hours per week. Overall, participants thus underwent a minimum of 45 hours (treatment dosage) of individualized language exercises during the first three weeks of the intervention.

\section{Identification of individual treatment targets}

Selection of individual initial SLT targets was based on baseline performance in two novel screening tools: (i) a language-systematic measure assessing receptive and expressive language functions at three levels of complexity and focusing on the core language domains of phonology, lexicon, and syntax (Sprachsystematisches APhasieScreening/SAPS) (12); (ii) a measure assessing communicative-pragmatic skills with a battery of nine tasks with increasing communicative demands, ranging from object identification and naming to complex role plays (KommunikativPragmatisches Screening/KOPS; Glindemann R. and Ziegler W., in preparation). All KOPS tasks were embedded in a communicative interaction, and responses were allowed in nonverbal communication modes like drawing or gesturing (whenever responses could not be given verbally). 
Intensive SLT improves verbal communication in chronic post-stroke aphasia For treatment of language-systematic deficits, the two domains demonstrating impairments at the lowest level of complexity in either the receptive or the expressive modality became initial treatment targets. If the impairment was equally severe in all three language domains, syntax was targeted prior to the lexicon, while phonology was targeted last. This hierarchy of treatment targets was motivated by the overall treatment goal of improving verbal communication effectiveness. Influential theories of language production (13) suggest that language processing at a syntactic level (as required when completing short sentence fragments) automatically activates lexical and phonological information (14). For patients with comparable impairments across phonological, lexical and syntactic domains, the predominant targeting of syntactic processing in SLT is therefore the most economical approach.

If receptive and expressive modalities were equally impaired within a linguistic domain, receptive functions were targeted prior to expressive functions. This hierarchy was selected because basic receptive functions are generally considered a prerequisite for improvements in expressive language functions (15). Furthermore, training sentence comprehension has been shown to generalize to sentence production ability, while the reverse facilitation has not been demonstrated (16-18).

Selection of treatment targets for communicative-pragmatic deficits was based on resource-oriented principles of functional communication therapy. The major principle here is to train patients' ability to receive or convey messages regardless of the mode to communicate effectively despite their language-systematic deficits in interactive settings. Specifically, the two least impaired types of tasks among those demonstrating a baseline performance of less than $80 \%$ correct were targeted for treatment. In the few cases where a patient performed $\geq 80 \%$ correct on each of the nine communicative tasks at baseline, the two most affected tasks among those showing relatively mild impairments (i.e., $\geq 80 \%$ correct) were targeted for treatment. The contents of the individual SLT were tailored along these selection criteria, and, whenever feasible, they also determined the content of the group sessions.

\section{Treatment manual}

Prior to inclusion of the first patient, a treatment manual (Grewe, T., Baumgaertner, A., Abel, S., Glindemann, R., Domahs, F., Regenbrecht, F., Schlenck, K.-J., \& Thomas, M., in preparation) was compiled to assist therapists in choosing appropriate modules for each patient's individual therapy targets. The manual also served to enhance 
Intensive SLT improves verbal communication in chronic post-stroke aphasia transparency and comparability of treatment administration across centres. It offered a range of modules from which appropriate exercises for a given patient could be selected (two language-systematic and two communicative-pragmatic targets, see section above). The exercises represent current best practice in SLT as agreed upon by the eight authors of the manual in several round table discussions.

The manual additionally reflects the underlying principles of the two screening measures SAPS and KOPS, and the treatment material contained in the manual resembles the SAPS and KOPS test stimuli in terms of linguistic structure and task demands. The language-systematic part of the manual offers treatment modules in the three core language domains (phonology, lexicon, and syntax). In the phonological domain, receptive tasks include syllable discrimination and identification, while expressive tasks require repetition of pseudowords of increasing complexity. In the lexical domain, receptive tasks include word-picture matching and decisions on synonymy and semantic features, while expressive tasks require production of increasingly complex object names upon picture presentation. In the receptive syntactic domain, patients are asked to identify the agent by forced choice between two pictures in orally presented sentences of increasing syntactic complexity; in the expressive syntactic domain, patients are asked to produce object-verb phrases, subject-verb-object structures, and complement clauses upon picture presentation.

The communicative-pragmatic part of the manual was based on the nine KOPS tasks with increasing communicative demands. They include

(i) object identification,

(ii) object naming,

(iii) basal communicative actions (e.g. expressing disagreement),

(iv) communication of personal and (v) general information,

(vi) comprehending or (vii) conveying street directions,

(viii) conveying complex messages in non-interactive role play situations, and

(ix) responding to non-cooperative communication partners in interactive role plays of everyday communicative situations.

Patients were encouraged to respond in any communication mode, i.e., with speech, hand gestures, writing, or drawing. 
Intensive SLT improves verbal communication in chronic post-stroke aphasia Prior to patient enrolment, participating SL therapists were thoroughly trained by the authors of the manual. This included the use of the manual and documentation in the respective forms. The SL therapists closely monitored patients' compliance with selfadministered exercises (frequently PC training) by going over the practice sheets/tasks together with the patient during the following treatment session. In addition, therapists frequently (usually after one week of treatment) mailed the completed therapy documentation forms (containing frequency, duration and type of treatment as well as type of task) to a supervisor assigned to their centre (i.e., one of the authors of the treatment manual). Based on these forms, supervisors gave feedback to the therapists regarding conformity with the therapy manual for at least $1 \mathrm{~h} /$ week per centre by telephone throughout the therapy phase. In addition, supervisors were available by telephone to discuss short-term decisions regarding therapy content and/or progression/regression for a given patient (see below) with the therapists.

\section{Treatment progression/regression}

Language-systematic treatment progressed in a standardized fashion to the next complexity level within a given linguistic domain/modality. If the highest level in the respective domain/modality was reached, treatment switched to the domain/modality 'next in line' according to baseline assessment. Likewise, communicative-pragmatic therapy targets were adjusted to treatment-induced changes in performance (progression or regression to the next communicative demand level). Progression in response to stable advance in performance, or regression to a lower complexity level in case of performance deterioration, was guided by a standardized treatment protocol. This included daily monitoring of patients' performance in the current therapy modules. Depending on the results of the monitoring, stable ceiling performance (> 80 percent correct) in a module resulted in progression to a more complex module, while a deterioration in performance led to regression to a less demanding treatment module. SLT duration and content were documented on a daily basis.

\section{Treatment per-protocol}

Pooled across groups, 136 of 156 patients were treated per protocol during the 3 -week critical SLT. The treatment of 15 patients showed minor protocol deviations (i.e., $\geq 24$ hours SLT were provided in weeks 1-3, but SLT was interrupted for up to three days because of minor medical problems or public holidays). Major deviations occurred in 
Intensive SLT improves verbal communication in chronic post-stroke aphasia

five patients (4 patients: <24 hours of SLT in weeks 1-3 and/or an interruption of SLT for 4-5 days; 1 patient: refusal to complete the self-managed linguistic exercises).

Importantly, no patient of either group (intensive SLT started after the 3-week waiting period in the control group) received less than 22.5 hours of SLT during the first three critical weeks of SLT, i.e., SLT was "intensive" (i.e., $\geq 5$ h/week) for all patients. 
Intensive SLT improves verbal communication in chronic post-stroke aphasia Further acknowledgements

The help of Elke Landsiedel (member of the executive board) and Dagmar Amslinger (CEO) of the German non profit self-help organization for persons with an acquired communication and language disorder caused by brain damage and their families and caregivers 'Bundesverband für die Rehabilitation der Aphasiker (BRA) [Federal Association for the Rehabilitation of Persons with Aphasia] in distributing study information and motivating potential study participants is greatly acknowledged. Elke Landsiedel also contributed greatly by her participation in the study's Trial Steering Committee.

We also thank Gerhard J. Jungehulsing (Department of Neurology, The Jewish Hospital Berlin, Germany) for his support in developing the medical history questionnaire used in the study and for providing the training material for assessing the mRS score.

The essential contributions of the endpoint committee members (http://fcet2ec.aphasiegesellschaft.de/index.php/uber-uns/endpoint-committee/) in scoring the primary outcome measure, and the diligent work of the FCET2EC study assessors (http://fcet2ec.aphasiegesellschaft.de/index.php/uber-uns/testleiter/) are greatly acknowledged.

Diana Van Lancker Sidtis' help in checking the final manuscript for style and spelling and Alexa Ziegeler's meticulousness in external data monitoring are greatly acknowledged. 
Intensive SLT improves verbal communication in chronic post-stroke aphasia

FCET2EC committees and coordinating centre

\section{Trial Steering Committee}

E Bernd Ringelstein (Chair), Walter Huber, Klaus Willmes, Jan Jungehülsing (until February 2013) Karl Georg Haeusler (starting March 2013), Peter Martus, Elke Landsiedel (Patient Delegate).

\section{Trial Coordinating Centre}

University Hospital Muenster. Department of Neurology: Caterina Breitenstein (local PI), Indra Hempen (starting July 2013), Christina Dirks (until June 2013), Roman Rocker, Franziska Wigbers, Christina Rühmkorf, Bastian Raudszus, Eva Oldenburg

\section{Endpoint Committee}

Christine Wendt, Ilona Rubi-Fessen, Katrin Johannsen, Kristina Thiele, Andrea Honekamp, Bianka Schramm, Kira Nicoline Kramer, Georg Newesely.

\section{Therapy Manual Authors}

Tanja Grewe, Steffie Abel, Frank Domahs, Ralf Glindemann, Frank Regenbrecht, Klaus-Jürgen Schlenck, Marion Thomas, Luise Springer (deceased in August 2011), Annette Baumgaertner 
Intensive SLT improves verbal communication in chronic post-stroke aphasia

\section{List of FCET2EC author (italics) and non-author collaborators}

Centre Coordinators (CC) are listed first for each site.

1. Max-Planck-Institut für Kognitions- und Neurowissenschaften Leipzig und Tagesklinik für Kognitive Neurologie: F Regenbrecht (CC), A Villringer, $H$ Obrig.

2. Brandenburg Klinik Bernau Waldfrieden: M Bley (CC), M Jöbges.

3. Neurologische Klinik, Lehr- und Forschungsgebiet Neurolinguistik, Universitätsklinikum Aachen: K Halm (CC), J Schulz, C Werner.

4. Städtisches Klinikum München Bogenhausen, Klinik für Neuropsychologie: $R$ Glindemann (CC), G Goldenberg, W Ziegler.

5. Aphasiestation der Neurologischen Klinik Bad Aibling am Standort Rosenheim: G Klingenberg (CC), E König, F Müller.

6. St. Mauritius Therapieklinik Meerbusch: B Gröne (CC), S Knecht.

7. Median-Klinik Grünheide, Berlin: R Baake (CC), J Knauss, , S Miethe.

8. m\&i Fachklinik Enzensberg: K-J Schlenck (CC), U Steller, R Sudhoff.

9. m\&i Fachklinik Bad Liebenstein: E Schillikowski (CC), G Pfeiffer.

10. Aphasiezentrum Josef Bergmann, Vechta: Kathrin Billo (CC), Hannah Hoffmann, F-J Ferneding.

11. Logopädisches und interdisziplinäres Behandlungszentrum für Intensivtherapie Lindlar: T Keck (CC), V Middeldorf, S Krüger.

12. Asklepios Neurologische Klinik Falkenstein: B Wilde (CC), K Krakow.

13. Wicker-Klinik Bad Homburg v.d.H.: C Berghoff (CC), F Reinhuber.

14. Akademische Praxis für Sprachtherapie/Neurologische Praxis Aschaffenburg: I Maser (CC), W. Hofmann.

15. m\&i Fachklinik Herzogenaurach: C Sous-Kulke (CC), W Schupp.

16. Gräfliche Kliniken Moritz Klinik Bad Klosterlausnitz: A Oertel (CC), D Bätz, F Hamzei.

17. MediClin Klinikum Soltau: K Schulz (CC), A Meyer.

18. Logopädische Ambulanz im Klinikum Christophsbad, Göppingen: A Kartmann (CC), O’N Som.

19. P.A.N.-Zentrum Berlin: S-B Schipke (CC), S Bamborschke. 
Intensive SLT improves verbal communication in chronic post-stroke aphasia

Reference List

1. Huber W, Poeck K, Willmes K. The Aachen Aphasia Test. Adv Neurol 1984;42:291-303.

2. Liepold, M., Ziegler, W., and Brendel, B. Hierarchische Wortlisten; Ein Nachsprechtest für die Sprechapraxiediagnostik [Hierarchical word lists: A repetition test for the assessment of speech apraxia]. (13). 2013. Dortmund, Germany, borgmann publishing $\mathrm{GmbH}$.

3. Rorden C, Karnath HO. A simple measure of neglect severity. Neuropsychologia 2010;48(9):2758-63.

4. Wechsler D. Wechsler Adult Intelligence Scale - Revised (WAIS-R). New York, USA: Psychological Corporation; 1981.

5. Wechsler D. Wechsler Memory Scale - Revised (WMS-R). San Antonio, TX, USA: The Psychological Corporation; 1987.

6. Amieva H, Gaestel Y, Dartigues JF. The multiple-choice formats (forms F and $\mathrm{G}$ ) of the Benton Visual Retention Test as a tool to detect age-related memory changes in population-based studies and clinical settings. Nat Protoc 2006;1(4):1936-8.

7. Oldfield RC. The assessment and analysis of handedness: the Edinburgh inventory. Neuropsychologia 1971;9(1):97-113.

8. Stern RA, Arruda JE, Hooper CR, Wolfner GD, Morey CE. Visual analogue mood scales to measure internal mood state in neurologically impaired patients: description and initial validity evidence. Aphasiology 1997;11(1):59-71.

9. Springer L. Therapeutic Approaches in Aphasia Rehabilitation. In: Stemmer B, Whitaker HA, editors. Handbook of the Neuroscience of Language. 1st ed. San Diego: Elsevier; 2008. p. 397-406.

10. Brady MC, Kelly H, Godwin J, Enderby P, Campbell P. Speech and language therapy for aphasia following stroke. Cochrane Database Syst Rev 2016;6:CDoo0425.

11. Galletta EE, Barrett AM. Impairment and Functional Interventions for Aphasia: Having it All. Curr Phys Med Rehabil Rep. 2014;2(2):114-20.

12. Bloemer F, Pesch A, Willmes K, Huber W, Springer L, Abel S. Das sprachsystematische Aphasiescreening (SAPS): Konstruktionseigenschaften und erste Evaluierung [The langugage-systematic aphasia screening (SAPS): construction features and first evaluation]. Z Neuropsych 2013;24(3):139-48.

13. Levelt WJM. Speaking. From intention to articulation. Cambridge,MA: MIT Press; 1989.

14. Hagoort P, Levelt WJ. Neuroscience. The speaking brain. Science 2009;326(5951):372-3. 
Intensive SLT improves verbal communication in chronic post-stroke aphasia

15. Pierce RA. Comprehension. In: Code C, Müller D, editors. Treatment of aphasia: From theory to practice. London, UK: Whurr Publishers Ltd.; 2002. p. 173-86.

16. Schroder A, Burchert F, Stadie N. Training-induced improvement of noncanonical sentence production does not generalize to comprehension: evidence for modality-specific processes. Cogn Neuropsychol 2015;32(3-4):195220 .

17. Jacobs BJ, Thompson CK. Cross-modal generalization effects of training noncanonical sentence comprehension and production in agrammatic aphasia. J Speech Lang Hear Res 2000;43(1):5-20.

18. Whitworth A, Webster J, Howard D. A cognitive neuropsychological approach to assessment and intervention in aphasia. London, UK: Psychology Press; 2014. 


\section{T犃ieR}

Template for Intervention Description and Replication

The TIDieR (Template for Intervention Description and Replication) Checklist*: Information to include when describing an intervention and the location of the information

\begin{tabular}{lll}
\hline $\begin{array}{l}\text { Item } \\
\text { number }\end{array}$ & Item & Where located ** \\
\hline 1. & BRIEF NAME & Primary paper (page or appendix number) \\
& Provide the name or a phrase that describes the intervention. & Routine individualized integrative speech and \\
& & $\begin{array}{l}\text { language therapy (SLT), combining language- } \\
\text { systematic and communicative-pragmatic approaches } \\
\end{array}$ \\
& & individualized to the baseline profile of each patient \\
& (in: Procedures; see also Supplemental Information)
\end{tabular}

2.

\section{WHY}

Describe any rationale, theory, or goal of the elements essential to the intervention.

3.

\section{WHAT}

Materials: Describe any physical or informational materials used in the intervention, including those provided to participants or used in intervention delivery or in training of intervention providers.

Provide information on where the materials can be accessed (e.g. online appendix, URL)
Intensive agreed-best-practice SLT, as only intensive therapy of a certain total dosage has been shown to be effective in chronic post-stroke aphasia

All treatment materials contained in Treatment Manual used by the participating therapists (in: Procedures;

see also Supplemental Information). Specifically, the Treatment Manual includes: guidelines for deducting the main foci of therapy; details of treatment procedures; criteria for item selection; verbal instructions to patients; stimulus pictures, letters, and pictograms; cueing strategies; references for further applicable treatment programs; available computerbased language therapy programs etc.) as well as monitoring and documentation forms, rating criteria, and guidelines for treatment progression (resp.

regression)

Other ${ }^{\dagger}$ (details)

Screening instruments

(Sprachsystematisches

APhasieScreening/SAPS and

Kommunikativ-Pragmatisches

Screening/KOPS) and treatment

Manual (under the name

ESKOPA) to be published by

Hogrefe

$---$

See above 
4. $\quad$ Procedures: Describe each of the procedures, activities, and/or processes used in the intervention, including any enabling or support activities.

5.

\section{WHO PROVIDED}

For each category of intervention provider (e.g. psychologist, nursing assistant), describe their expertise, background and any specific training given.

\section{6.}

\section{HOW}

Describe the modes of delivery (e.g. face-to-face or by some other mechanism, such as internet or telephone) of the intervention and whether it was provided individually or in a group.
Individual and group therapy led by speech-language therapist extensively trained in the use of the Treatment Manual; self-managed PC-training customized to individual patients' primary linguistic deficits. Daily documentation of content and duration of therapy by treating therapists; regular monitoring of treatment conformity by centre supervisors (i.e. the authors of the Treatment Manual) (in: Procedures; see also Supplemental Information)

Professional speech and language therapists who conducted therapy as part of their clinical routine and who had been extensively trained in using the Therapy Manual by the authors of the Manual to select exercises conforming with patients' initial therapy goals, rate patients' performance during daily monitoring, adjust therapy content according to the results of the daily monitoring (if necessary after consulting with the centre supervisor), and complete the documentation forms

Face-to-face individual and group therapy (recommended group size: between 2 and 4 participants) led by speech-language therapists extensively trained in the use of the Treatment Manual; self-managed PC-training customized to individual patients' primary linguistic deficits (in: Procedures; see also Supplemental Information) 


\section{WHERE}

Describe the type(s) of location(s) where the intervention occurred, including any necessary infrastructure or relevant features.

\section{WHEN and HOW MUCH}

Describe the number of times the intervention was delivered and over what period of time including the number of sessions, their schedule, and their duration, intensity or dose.

\section{TAILORING}

If the intervention was planned to be personalised, titrated or adapted, then describe what, why, when, and how
Treatment conducted in the participating rehabilitation centres as part of the clinical routine

\section{$---$}

Therapist-guided daily treatment for at least $10 \mathrm{~h}$ per week (usually $2 \mathrm{~h}$ per day), over the course of at least 3 weeks (a subgroup of patients was granted extension of intensive SLT by their respective health care providers) plus $\geq 5$ hours/week self-managed PCtraining targeting individual linguistic deficits.

Treatment sessions lasted between $30 \mathrm{~min}$ and 1 hour and were scheduled individually for each patient by the rehabilitation facility, depending on a patient's overall therapy regimen (details in Supplemental Information)

Treatment was tailored to each patient's individual language profile/deficits. Selection of individual initial SLT targets was based on baseline performance in two novel screening tools (see Supplemental Information for details): a language-systematic measure assessing receptive and expressive language functions at three levels of complexity and focusing on core language domains (SAPS), and a measure assessing communicative-pragmatic skills with a battery of nine tasks with increasing communicative demands (KOPS). Treatment progressed (or regressed) depending on a patient's individual performance on daily monitoring items reflecting a patient's current therapy targets 


\section{0..$^{\ddagger} \quad$ MODIFICATIONS}

If the intervention was modified during the course of the study, describe the changes (what, why, when, and how).

\section{HOW WELL}

Planned: If intervention adherence or fidelity was assessed, describe how and by whom, and if any strategies were used to maintain or improve fidelity, describe them.

12. $\quad$ Actual: If intervention adherence or fidelity was assessed, describe the extent to which the intervention was delivered as planned.
No modifications were implemented regarding the procedures described in the Therapy Manual.

Planned: Therapists mailed the completed therapy documentation forms - usually after one week of therapy - to the supervisor assigned to their centre (i.e., one of the authors of the treatment manual). Based on these forms, supervisors gave feedback to the therapists regarding conformity with the therapy manual for at least $1 \mathrm{~h}$ /week per centre by telephone throughout the therapy phase. In addition, supervisors were available by telephone throughout the treatment phase to discuss short-term decisions regarding therapy content and/or progression/regression for a given patient with the therapists.

Actual: All patients $(n=156)$ completed the treatment. Pooled across groups, 136 of 156 patients were treated per protocol during the 3-week critical SLT. Treatment of 15 patients showed minor protocol deviations (i.e., $\geq 24$ hours SLT were provided in weeks 1-3, but SLT was interrupted for up to three days because of minor medical problems or public holidays). Major deviations occurred in five patients (4 patients: $<24$ hours of SLT in weeks 1-3 and/or an interruption of SLT for 4-5 days; 1 patient: refusal to complete the 
self-managed language-systematic exercises).

Importantly, no patient of either group (intensive SLT

started after the 3-week waiting period in the control

group) received less than 22.5 hours of SLT during the

first three critical weeks of SLT, i.e., SLT was

"intensive" (i.e., $\geq 5 \mathrm{~h} /$ week) for all patients (see

Supplemental Information, Treatment-per-protocol).

** Authors - use N/A if an item is not applicable for the intervention being described. Reviewers - use '?' if information about the element is not reported/not sufficiently reported.

$\dagger$ If the information is not provided in the primary paper, give details of where this information is available. This may include locations such as a published protocol or other published papers (provide citation details) or a website (provide the URL).

‡ If completing the TIDieR checklist for a protocol, these items are not relevant to the protocol and cannot be described until the study is complete.

* We strongly recommend using this checklist in conjunction with the TIDieR guide (see BMJ 2014;348:g1687) which contains an explanation and elaboration for each item.

* The focus of TIDieR is on reporting details of the intervention elements (and where relevant, comparison elements) of a study. Other elements and methodological features of studies are covered by other reporting statements and checklists and have not been duplicated as part of the TIDieR checklist. When a randomised trial is being reported, the TIDieR checklist should be used in conjunction with the CONSORT statement (see www.consort-statement.org) as an extension of Item 5 of the CONSORT 2010 Statement When a clinical trial protocol is being reported, the TIDieR checklist should be used in conjunction with the SPIRIT statement as an extension of Item 11 of the SPIRIT 2013 Statement (see www.spirit-statement.org). For alternate study designs, TIDieR can be used in conjunction with the appropriate checklist for that study design (see www.equatornetwork.org). 


\section{Suppl. Table 1: Additional baseline characteristics and therapy data}

\begin{tabular}{|c|c|c|c|}
\hline Variable & & Immediate SLT group & Control group \\
\hline & & $(\mathrm{n}=78)^{*}$ & $(n=78) *$ \\
\hline \multicolumn{4}{|l|}{ Demographics } \\
\hline $\begin{array}{l}\text { Handedness - EHI laterality quotient } \\
(\text { mean }+/- \text { SD), range: }-1 \text { to } 1\end{array}$ & & $0 \cdot 79+/-0 \cdot 34$ & $0 \cdot 81+/-0 \cdot 42$ \\
\hline \multicolumn{4}{|l|}{ Stroke } \\
\hline \multirow{3}{*}{ Affected hemisphere (n) } & Unilateral left hemisphere stroke & $76(97 \%)$ & $74(95 \%)$ \\
\hline & Unilateral right hemisphere stroke & 0 & $1(1 \%)$ \\
\hline & bilateral stroke & $2(3 \%)$ & $3(4 \%)$ \\
\hline Initial thrombolysis (n) & & $15(19 \%)$ & $28(36 \%)$ \\
\hline Initial hemicraniectomy (n) & & $15(19 \%)$ & $20(26 \%)$ \\
\hline \multirow{5}{*}{$\begin{array}{l}\text { TOAST classification of (ischemic) index } \\
\text { stroke } \\
\text { (Immediate SLT group: } \mathrm{n}=64 \\
\text { Control group: } \mathrm{n}=67 \text { ) }\end{array}$} & large-artery atherosclerosis & $19(30 \%)$ & $24(36 \%)$ \\
\hline & cardioembolism & $11(17 \%)$ & $9(13 \%)$ \\
\hline & small-vessel occlusion & $\mathrm{O}$ & $\mathrm{O}$ \\
\hline & stroke of other determined etiology & $20(31 \%)$ & $13(19 \%)$ \\
\hline & stroke of undetermined etiology & $14(22 \%)$ & $21(31 \%)$ \\
\hline \multicolumn{4}{|l|}{ Behavioural stroke risk factors } \\
\hline \multirow{3}{*}{$\begin{array}{l}\text { Current or past smoking } \\
\text { (Immediate SLT group: } \mathrm{n}=50 \\
\text { Control group: } \mathrm{n}=53 \text { ) }\end{array}$} & quitted $>12$ months ago & $21(42 \%)$ & $28(53 \%)$ \\
\hline & current smoker & $29(58 \%)$ & $25(47 \%)$ \\
\hline & no. of pack-years (M +/-SD) & $22 \cdot 9+/-22 \cdot 5$ & $20 \cdot 0+/-18 \cdot 8$ \\
\hline \multirow{5}{*}{ Alcohol consumption (n) } & abstinent & $12(15 \%)$ & $11(14 \%)$ \\
\hline & 1-3 times per week & $54(69 \%)$ & $57(73 \%)$ \\
\hline & 4-6 times per week & $1(1 \%)$ & $5(6 \%)$ \\
\hline & daily & $10(13 \%)$ & $4(5 \%)$ \\
\hline & missing information & $1(1 \%)$ & $1(1 \%)$ \\
\hline \multicolumn{4}{|l|}{ Aphasia, apraxia of speech } \\
\hline \multirow{6}{*}{$\begin{array}{l}\text { AAT, spontaneous speech - raw scores, } \\
\text { range: o-5 (median; min.-max., Q1-Q3) }\end{array}$} & communicative ability & $2 ; 1-4 ; 1-3$ & $2 \cdot 50 ; 1-5 ; 1 \cdot 75-3$ \\
\hline & articulation and prosody & $4 ; 1-5 ; 3-5$ & $4 ; 2-5 ; 3-4$ \\
\hline & automated speech & $4 ; 0-5 ; 3-5$ & $4 ; 1-5: 3-5$ \\
\hline & semantic structure & $3 \cdot 5 ; 0-4 ; 3-4$ & $3 ; 0-5 ; 3-4$ \\
\hline & phonematic structure & $4 ; 0-5 ; 3-5$ & $4 ; 0-5 ; 3-4 \cdot 25$ \\
\hline & syntactic structure & $2 ; 0-5 ; 1-4$ & $2 ; 0-5 ; 1-4$ \\
\hline
\end{tabular}




\begin{tabular}{|c|c|c|c|}
\hline Variable & & Immediate SLT group & Control group \\
\hline \multicolumn{2}{|l|}{ Cont'd. Aphasia, apraxia of speech } & $(\mathrm{n}=78)^{*}$ & $(\mathrm{n}=78)^{*}$ \\
\hline \multirow{5}{*}{ AAT, subtests - T scores (M +/- SD) } & Token Test & $50 \cdot 12+/-7 \cdot 14(n=77)$ & $51 \cdot 77+/ 8 \cdot 17$ \\
\hline & repetition & $51 \cdot 45+/-6 \cdot 34(n=76)$ & $52 \cdot 40+/-6 \cdot 22(n=75)$ \\
\hline & written language & $49 \cdot 95+/-8 \cdot 90(n=77)$ & $51 \cdot 51+/-6 \cdot 27(n=77)$ \\
\hline & naming & $51 \cdot 68+/-7 \cdot 47(n=76)$ & $53 \cdot 16+/-7 \cdot 12(n=77)$ \\
\hline & comprehension & $53 \cdot 67+/-7 \cdot 80(n=76)$ & $54 \cdot 62+/-8 \cdot 78$ \\
\hline $\begin{array}{l}\text { Apraxia of speech - HWL, no. correct items, } \\
\text { Range: } 0-48 \text { (M +/- SD) }\end{array}$ & & $32 \cdot 86+/-14 \cdot 64$ & $32 \cdot 65+/-13 \cdot 52(n=77)$ \\
\hline \multicolumn{4}{|l|}{ General cognition } \\
\hline $\begin{array}{l}\text { Neglect (Bells Test), } \\
\text { Center of cancellation score }>0 \cdot 081 \text { (n) }\end{array}$ & & 2 & 2 \\
\hline $\begin{array}{l}\text { WAIS-R picture completion } \\
\text { - raw score, max score: } 17(\mathrm{M}+/-\mathrm{SD})\end{array}$ & & $7 \cdot 95+/-4 \cdot 52$ & $8 \cdot 44+/-3.98$ \\
\hline $\begin{array}{l}\text { BVRT - no. correct responses, max. } 15 \\
\text { (median; min.-max., Q1-Q3) }\end{array}$ & & $12 ; 2-15 ; 10-13(n=77)$ & $12 ; 4-15 ; 10-13$ \\
\hline \multirow{2}{*}{ WMS-R, verbal spans - raw score $(\mathrm{M}+/-\mathrm{SD})$} & forward & $1 \cdot 99+/-2 \cdot 02(n=76)$ & $2 \cdot 40+/-2 \cdot 18(n=77)$ \\
\hline & backward & $1 \cdot 85+/-1 \cdot 79(n=75)$ & $1.96+/-1.67(n=75)$ \\
\hline \multirow{2}{*}{$\begin{array}{l}\text { WMS-R, visual spans - raw score } \\
(\mathrm{M}+/-\mathrm{SD})\end{array}$} & forward & $6 \cdot 52+/-2 \cdot 00(n=77)$ & $6 \cdot 56+/-1 \cdot 87$ \\
\hline & backward & $5 \cdot 61+/-2 \cdot 47(n=77)$ & $5 \cdot 28+/-2 \cdot 06$ \\
\hline NVLT - hits minus false alarms (M +/- SD) & & $16 \cdot 84+/-8 \cdot 74(n=74)$ & $13 \cdot 53+/-9 \cdot 26(n=76)$ \\
\hline \multirow[b]{2}{*}{ TMT - sec until completion $(\mathrm{M}+/-\mathrm{SD})$} & version A (time limit: $180 \mathrm{sec}$ ) & $76 \cdot 09+/-41 \cdot 13(n=69)$ & $76 \cdot 54+/-35 \cdot 20(n=70)$ \\
\hline & version B (time limit: $300 \mathrm{sec}$ ) & $188 \cdot 08+/-60 \cdot 78(n=40)$ & $\begin{array}{c}181 \cdot 26+/-60 \cdot 80 \\
(n=38)\end{array}$ \\
\hline \multicolumn{4}{|l|}{ Additional therapy data } \\
\hline \multirow{3}{*}{ Therapy setting (n) } & inpatient & $34(44 \%)$ & $34(44 \%)$ \\
\hline & day clinic & $37(47 \%)$ & $38(49 \%)$ \\
\hline & outpatient & $7(9 \%)$ & $6(8 \%)$ \\
\hline \multicolumn{4}{|l|}{ Therapy weeks 1-3 (all patients) } \\
\hline $\begin{array}{l}\text { SLT treatment days with at least } 60 \text { min in } \\
\text { weeks 1-3 (median; min.-max., Q1-Q3) }\end{array}$ & & $15 ; 11-18 ; 15-16$ & $15 ; 12-19 ; 14-16$ \\
\hline $\begin{array}{l}\text { Days of SLT treatment interruption in weeks } \\
\text { 1-3 (median; min.-max., Q1-Q3) }\end{array}$ & & $0 ; 0-5 ; 0-1$ & $0 ; 0-2 ; 0-1$ \\
\hline
\end{tabular}




\begin{tabular}{|c|c|c|c|}
\hline Variable & & Immediate SLT group & Control group \\
\hline \multicolumn{4}{|l|}{ Cont'd· Additional therapy data } \\
\hline \multicolumn{2}{|c|}{ Subgroup with > 3 weeks of treatment: Entire intensive SLT period } & $\mathrm{n}=19$ & $\mathrm{n}=15$ \\
\hline $\begin{array}{l}\text { SLT treatment days with at least } 60 \mathrm{~min} \\
\text { until end of treatment } \\
\text { (median; min.-max., Q1-Q3) }\end{array}$ & & $27 ; 21-37 ; 25-31$ & $28,24-34 ; 25-31$ \\
\hline $\begin{array}{l}\text { Days of SLT treatment interruption until end } \\
\text { of study treatment } \\
\text { (median; min.-max., Q1-Q3) }\end{array}$ & & $2 ; 0-6 ; 1-3$ & $1 ; 0-6 ; 0-3$ \\
\hline \multirow{3}{*}{$\begin{array}{l}\text { SLT treatment hours until end of study } \\
\text { treatment } \\
\text { (median; min.-max., Q1-Q3) }\end{array}$} & total with SL therapist & $51 \cdot 8 ; 34-84 ; 47 \cdot 2-58$ & $48 ; 37 \cdot 4-76 ; 44-56 \cdot 8$ \\
\hline & \begin{tabular}{|l|} 
one-to-one \\
\end{tabular} & $33 \cdot 1 ; 25-48 ; 31 \cdot 8-39$ & $34 ; 28-55 ; 31-39$ \\
\hline & group sessions & $17 ; 9-36 ; 12 \cdot 8-19$ & $15 ; 8 \cdot 9-21 ; 10-20$ \\
\hline $\begin{array}{l}\text { Hours of self-managed language exercises } \\
\text { until end of study treatment } \\
\text { (median; min·-max., Q1-Q3) }\end{array}$ & & $28,21-36 ; 25-31$ & $28 ; 25-34 ; 25-33$ \\
\hline \multirow{3}{*}{$\begin{array}{l}\text { Non-SLT treatment hours until end of study } \\
\text { treatment (median; min.-max., Q1-Q3) }\end{array}$} & physiotherapy & $12 ; 0-46 ; 7 \cdot 5-23$ & $13 \cdot 5 ; 0-32 ; 8-30$ \\
\hline & occupational therapy & $4 ; 0-18 \cdot 8 ; 0-7 \cdot 5$ & $5 \cdot 5 ; 0-30 ; 0-12$ \\
\hline & cognitive therapy & $0 ; 0-9.5 ; 0-7$ & $0 ; 0-10 ; 0-1$ \\
\hline
\end{tabular}

\section{Follow-up period (6 months) \\ Total hours of SLT during 6 months follow- \\ up period (median; min.-max., Q1-Q3)}

$\mathrm{n}=77$

$\mathrm{n}=77$

3-week waiting period $(n=78)$

Total hours of treatment during the 3 weeks

of waiting (median; min.-max., Q1-Q3)

$27 \cdot 8 ; 0-101 \cdot 5 ; 15 \cdot 7-39 \cdot 3$

$30 ; 0-102 ; 19-42 \cdot 8$

*: in case of missing data: $\mathrm{n}$ of available data reported; ; SLT = Speech Language Therapy; $\mathrm{M}=$ mean; SD = standard deviation; $\mathrm{Q} 1$ = first quartile, $\mathrm{Q} 3$ = third quartile; AAT = Aachen Aphasia Test; HWL = Hierarchical Word Lists; WAIS = Wechsler Adult Intelligence Scale, Revised; BVRT = Benton Visual Recognition Test; WMS-R = Wechsler Memory Scale - Revised; NVLT = Nonverbal Learning Test; TMT = Trail Making Test n/a = not applicable 
Suppl. Table 2: Longterm primary and secondary treatment effects (comparison of pre-therapy to six months post SLT)

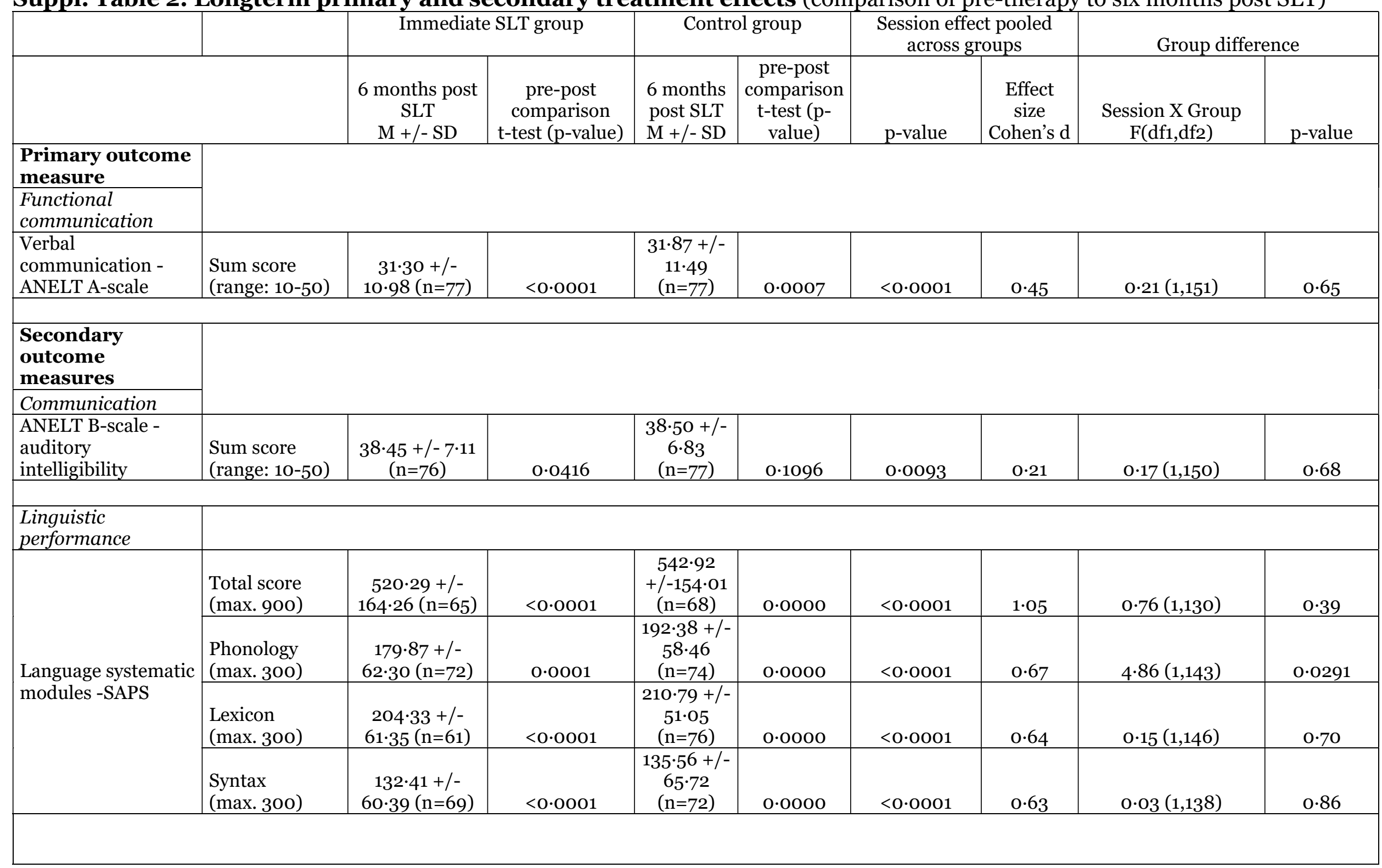




\begin{tabular}{|c|c|c|c|c|c|c|c|c|c|}
\hline & & \multicolumn{2}{|c|}{ Immediate SLT group } & \multicolumn{2}{|c|}{ Control group } & \multicolumn{2}{|c|}{$\begin{array}{c}\text { Session effect pooled } \\
\text { across groups }\end{array}$} & \multicolumn{2}{|c|}{ Group difference } \\
\hline & & $\begin{array}{c}6 \text { months post } \\
\text { SLT } \\
\mathrm{M}+/-\mathrm{SD} \\
\end{array}$ & $\begin{array}{c}\text { pre-post } \\
\text { comparison } \\
\text { t-test (p-value) }\end{array}$ & $\begin{array}{l}6 \text { months } \\
\text { post SLT } \\
\mathrm{M}+/-\mathrm{SD}\end{array}$ & $\begin{array}{c}\text { pre-post } \\
\text { comparison } \\
\text { t-test (p- } \\
\text { value) } \\
\end{array}$ & $\mathrm{p}$-value & $\begin{array}{c}\text { Effect } \\
\text { size } \\
\text { Cohen's d } \\
\end{array}$ & $\begin{array}{c}\text { Session X Group } \\
\text { F(df1,df2) } \\
\end{array}$ & $\mathrm{p}$-value \\
\hline \multirow{2}{*}{$\begin{array}{l}\text { Language systematic } \\
\text { modules -SAPS }\end{array}$} & $\begin{array}{l}\text { Language } \\
\text { comprehension } \\
(\max .324) \\
\end{array}$ & $\begin{array}{c}211 \cdot 58+/- \\
57 \cdot 69(\mathrm{n}=67)\end{array}$ & $<0 \cdot 0001$ & $\begin{array}{c}218 \cdot 45+/- \\
51 \cdot 70 \\
(n=73)\end{array}$ & $<0 \cdot 0001$ & $<0 \cdot 0001$ & 0.78 & $0 \cdot 17(1,137)$ & $0 \cdot 68$ \\
\hline & $\begin{array}{l}\text { Language } \\
\text { production } \\
(\max .576) \\
\end{array}$ & $\begin{array}{c}313 \cdot 29+/- \\
135 \cdot 14(\mathrm{n}=73)\end{array}$ & $<0 \cdot 0001$ & $\begin{array}{c}326 \cdot 43 \\
+/-127 \cdot 92 \\
(n=72)\end{array}$ & $<0 \cdot 0001$ & $<0 \cdot 0001$ & $0 \cdot 68$ & $0 \cdot 44(1,142)$ & $0 \cdot 51$ \\
\hline \multicolumn{10}{|l|}{ Quality of life } \\
\hline \multicolumn{10}{|l|}{ Patient's view } \\
\hline \multirow{5}{*}{$\begin{array}{l}\text { SAQOL-39 } \\
\text { (item scores ranging } \\
\text { from 1-5) }\end{array}$} & $\begin{array}{l}\text { Total score } \\
\text { (39 items) }\end{array}$ & $\begin{array}{c}3 \cdot 83+/-0 \cdot 61 \\
(n=76)\end{array}$ & $0 \cdot 0070$ & $\begin{array}{c}3 \cdot 70+/- \\
0 \cdot 73 \\
(n=77)\end{array}$ & $0 \cdot 0444$ & $0 \cdot 0009$ & $0 \cdot 24$ & $0 \cdot 30(1,150)$ & 0.59 \\
\hline & $\begin{array}{l}\text { Physical score } \\
\text { (17 items) }\end{array}$ & $\begin{array}{c}4 \cdot 12+/-0 \cdot 67 \\
(n=76)\end{array}$ & $0 \cdot 37$ & $\begin{array}{c}4 \cdot 02+/- \\
0 \cdot 78 \\
(n=77)\end{array}$ & $0 \cdot 0174$ & $0 \cdot 0202$ & $0 \cdot 19$ & $0 \cdot 36(1,150)$ & 0.55 \\
\hline & $\begin{array}{l}\text { Communica- } \\
\text { tion score } \\
\text { ( } 7 \text { items) }\end{array}$ & $\begin{array}{c}3 \cdot 11+/-0 \cdot 86 \\
(n=76)\end{array}$ & $0 \cdot 0001$ & $\begin{array}{c}3 \cdot 03+/- \\
0 \cdot 98 \\
(n=77)\end{array}$ & $<0 \cdot 0001$ & $<0 \cdot 0001$ & $0 \cdot 49$ & $0 \cdot 00(1,150)$ & 0.99 \\
\hline & $\begin{array}{l}\text { Psychosocial } \\
\text { score } \\
\text { (11 items) } \\
\end{array}$ & $\begin{array}{c}3 \cdot 85+/-0 \cdot 83 \\
(n=76)\end{array}$ & $0 \cdot 0120$ & $\begin{array}{c}3 \cdot 61+/- \\
0 \cdot 94 \\
(n=77) \\
\end{array}$ & 0.69 & $0 \cdot 20$ & $0 \cdot 10$ & $4 \cdot 41(1,150)$ & $0 \cdot 0374$ \\
\hline & $\begin{array}{l}\text { Energy score ( } 4 \\
\text { items) }\end{array}$ & $\begin{array}{c}3 \cdot 78+/-0 \cdot 92 \\
(n=76)\end{array}$ & 0.63 & $\begin{array}{c}3 \cdot 77+/- \\
0 \cdot 94 \\
(n=77) \\
\end{array}$ & $0 \cdot 95$ & $0 \cdot 78$ & $0 \cdot 02$ & $0 \cdot 08(1,150)$ & $0 \cdot 78$ \\
\hline \multicolumn{10}{|l|}{$\begin{array}{l}\text { Significant other's } \\
\text { view }\end{array}$} \\
\hline CETI & $\begin{array}{l}\text { Total score } \\
\text { (range: } 16-160 \text { ) }\end{array}$ & $\begin{array}{c}94 \cdot 31+/- \\
32 \cdot 68(n=67)\end{array}$ & $0 \cdot 0047$ & $\begin{array}{c}92 \cdot 04+/- \\
28 \cdot 59 \\
(n=72) \\
\end{array}$ & $0 \cdot 0021$ & $<0 \cdot 0001$ & $0 \cdot 37$ & $0 \cdot 14(1,136)$ & $0 \cdot 71$ \\
\hline
\end{tabular}




\begin{tabular}{|c|c|c|c|c|c|c|c|c|c|}
\hline & & \multicolumn{2}{|c|}{ Immediate SLT group } & \multicolumn{2}{|c|}{ Control group } & \multicolumn{2}{|c|}{$\begin{array}{l}\text { Session effect pooled } \\
\text { across groups }\end{array}$} & \multicolumn{2}{|c|}{ Group difference } \\
\hline & & $\begin{array}{c}6 \text { months post } \\
\text { SLT } \\
\mathrm{M}+/-\mathrm{SD}\end{array}$ & $\begin{array}{c}\text { pre-post } \\
\text { comparison } \\
\text { t-test (p-value) }\end{array}$ & $\begin{array}{l}6 \text { months } \\
\text { post SLT } \\
\mathrm{M}+/-\mathrm{SD}\end{array}$ & \begin{tabular}{|c|} 
pre-post \\
comparison \\
t-test (p- \\
value) \\
\end{tabular} & $\mathrm{p}$-value & $\begin{array}{c}\text { Effect } \\
\text { size } \\
\text { Cohen's d } \\
\end{array}$ & $\begin{array}{c}\text { Session X Group } \\
\text { F(df1, df2) }\end{array}$ & p-value \\
\hline \multicolumn{10}{|c|}{$\begin{array}{l}\text { Nonverbal cognitive } \\
\text { functioning }\end{array}$} \\
\hline NVLT & $\begin{array}{l}\text { Hits minus } \\
\text { false alarms }\end{array}$ & $\begin{array}{c}20 \cdot 24+/-9 \cdot 50 \\
(n=72)\end{array}$ & $0 \cdot 0007$ & $\begin{array}{c}17 \cdot 45+/- \\
10 \cdot 52 \\
(n=75) \\
\end{array}$ & $0 \cdot 0000$ & $<0 \cdot 0001$ & $0 \cdot 47$ & $0.93(1,144)$ & $0 \cdot 34$ \\
\hline \multirow{2}{*}{$\begin{array}{l}\text { TMT } \\
\text { - sec until } \\
\text { completion }\end{array}$} & $\begin{array}{l}\text { version A } \\
\text { (max. 180 sec) }\end{array}$ & $\begin{array}{c}60 \cdot 86+/- \\
35 \cdot 13(n=61)\end{array}$ & $0 \cdot 0138$ & \begin{tabular}{|c|}
$62 \cdot 79+/-$ \\
$28 \cdot 24$ \\
$(n=67)$ \\
\end{tabular} & $0 \cdot 0004$ & $<0 \cdot 0001$ & $-0 \cdot 39$ & $0 \cdot 003(1,125)$ & $0 \cdot 96$ \\
\hline & $\begin{array}{l}\text { version B } \\
(\max 300 \mathrm{sec})\end{array}$ & $\begin{array}{c}153 \cdot 97+/- \\
50 \cdot 88(n=35)\end{array}$ & $0 \cdot 0004$ & $\begin{array}{c}146 \cdot 29+/- \\
47 \cdot 49 \\
(n=35) \\
\end{array}$ & 0.0029 & $<0 \cdot 0001$ & -0.60 & $0 \cdot 14(1,67)$ & $0 \cdot 71$ \\
\hline \multicolumn{10}{|l|}{ Stroke severity } \\
\hline $\begin{array}{l}\text { modified Rankin } \\
\text { Scale }\end{array}$ & $\begin{array}{l}\text { score } \\
\text { (range: } 0-6 \text { ) }\end{array}$ & $\begin{array}{c}2 \cdot 14+/-0 \cdot 73 \\
(n=76)\end{array}$ & $0 \cdot 38$ & $\begin{array}{c}2 \cdot 19+/- \\
0 \cdot 84 \\
(n=77) \\
\end{array}$ & $0 \cdot 0086$ & 0.0094 & $-0 \cdot 21$ & $0.95(1,150)$ & $0 \cdot 33$ \\
\hline
\end{tabular}

M = mean; SD = standard deviation; SLT = Speech Language Therapy; ANELT = Amsterdam Nijmegen Everyday Language Test; SAPS = Sprachsystematisches Aphasiescreening [langugage-systematic aphasia screening]; SAQOL-39 = Stroke and Aphasia Quality of Life Scale-39; CETI = Communicative Effectiveness Index; NVLT = Nonverbal Learning Test; TMT = Trail Making Test.

The effect size Cohen's d refers to the average group difference (and standard deviations) of the differences from pre to post assessments. The sign "-" has been chosen when the result was in favour of the waiting group, regardless of scale orientation. 


\section{Suppl. Table 3: Immediate primary and secondary language treatment effects in the control group} (after the waiting period)

\begin{tabular}{|c|c|c|c|c|c|c|}
\hline & \multirow{2}{*}{$\begin{array}{l}\text { Group difference } \\
\text { (SLT vs. control group): } \\
\text { Comparison of pre to } \\
\text { post } 3 \text { weeks of SLT }\end{array}$} \\
\hline & & pre 3 weeks waiting & post 3 weeks SLT & & $\begin{array}{l}\text { Comparison of pre to } \\
\text { post } 3 \text { weeks of SLT }\end{array}$ & \\
\hline & & $\mathrm{M}+/-\mathrm{SD}$ & $\mathrm{M}+/-\mathrm{SD}$ & n (post 3 weeks SLT) & p-value & p-value \\
\hline & & $\begin{array}{c}\text { (data also reported } \\
\text { in Table 2) }\end{array}$ & & & & \\
\hline \multicolumn{7}{|l|}{$\begin{array}{l}\text { Primary outcome } \\
\text { measure }\end{array}$} \\
\hline $\begin{array}{l}\text { Verbal } \\
\text { communication - } \\
\text { ANELT A-scale }\end{array}$ & $\begin{array}{l}\text { Sum score } \\
\text { (range: } 10-50)\end{array}$ & $29 \cdot 63+/-10 \cdot 94$ & $32 \cdot 17+/-11 \cdot 56$ & 78 & $<0 \cdot 0001$ & 0.99 \\
\hline \multicolumn{7}{|l|}{$\begin{array}{l}\text { Secondary } \\
\text { outcome } \\
\text { measures } \\
\end{array}$} \\
\hline \multicolumn{7}{|l|}{ Communication } \\
\hline $\begin{array}{l}\text { ANELT B-scale - } \\
\text { auditory } \\
\text { intelligibility }\end{array}$ & $\begin{array}{l}\text { Sum score } \\
\text { (range: } 10-50)\end{array}$ & $37 \cdot 61+/-6 \cdot 85$ & $37 \cdot 99+/-7 \cdot 13$ & 78 & $0 \cdot 35$ & 0.60 \\
\hline \multicolumn{7}{|l|}{$\begin{array}{l}\text { Linguistic } \\
\text { performance }\end{array}$} \\
\hline \multirow{4}{*}{$\begin{array}{l}\text { Language systematic } \\
\text { modules - SAPS }\end{array}$} & $\begin{array}{l}\text { Total score } \\
(\max .900)\end{array}$ & $469 \cdot 32+/-144 \cdot 33$ & $537 \cdot 27+/ 149 \cdot 51$ & 72 & $<0 \cdot 0001$ & $0 \cdot 77$ \\
\hline & $\begin{array}{l}\text { Phonology } \\
\text { (max. 300) }\end{array}$ & $167 \cdot 84+/-60 \cdot 97$ & $192 \cdot 73+/-61 \cdot 09$ & 76 & $<0 \cdot 0001$ & $0 \cdot 12$ \\
\hline & $\begin{array}{l}\text { Lexicon } \\
\text { (max. 300) }\end{array}$ & $193 \cdot 06+/-53 \cdot 63$ & $213 \cdot 43+/-49 \cdot 41$ & 78 & $<0 \cdot 0001$ & $0 \cdot 40$ \\
\hline & Syntax (max. 300) & $106 \cdot 40+/-59 \cdot 00$ & $132 \cdot 81+/-67 \cdot 98$ & 76 & $<0 \cdot 0001$ & $0 \cdot 41$ \\
\hline
\end{tabular}




\begin{tabular}{|c|c|c|c|c|c|c|}
\hline & & pre 3 weeks waiting & post 3 weeks SLT & & $\begin{array}{l}\text { Comparison of pre to } \\
\text { post } 3 \text { weeks of SLT }\end{array}$ & $\begin{array}{l}\text { Group difference } \\
\text { (SLT vs. control group): } \\
\text { Comparison of pre to } \\
\text { post } 3 \text { weeks of SLT }\end{array}$ \\
\hline & & $\mathrm{M}+/-\mathrm{SD}$ & $\mathrm{M}+/-\mathrm{SD}$ & n (post 3 weeks SLT) & $\mathrm{p}$-value & p-value \\
\hline & & $\begin{array}{c}\text { (data also reported } \\
\text { in Table 2) }\end{array}$ & & & & \\
\hline \multirow{2}{*}{$\begin{array}{l}\text { Language systematic } \\
\text { modules - SAPS }\end{array}$} & $\begin{array}{l}\text { Language } \\
\text { comprehension } \\
(\max .324)\end{array}$ & $190 \cdot 97+/-53 \cdot 62$ & $214 \cdot 38+/-50 \cdot 23$ & 76 & $<0 \cdot 0001$ & $0 \cdot 31$ \\
\hline & $\begin{array}{l}\text { Language } \\
\text { production } \\
(\max .576) \\
\end{array}$ & $287 \cdot 76+/-117 \cdot 61$ & $338 \cdot 36+/-127 \cdot 36$ & 77 & $<0 \cdot 0001$ & $0 \cdot 09$ \\
\hline \multicolumn{7}{|l|}{ Quality of life } \\
\hline \multirow{5}{*}{$\begin{array}{l}\text { Patient's view - } \\
\text { SAQOL-39 } \\
\text { (item scores ranging } \\
\text { from 1-5) }\end{array}$} & \begin{tabular}{|l|}
$\begin{array}{l}\text { Total score } \\
\text { (39 items) }\end{array}$ \\
\end{tabular} & $3 \cdot 58+/-0 \cdot 61$ & $3 \cdot 76+/-0 \cdot 59$ & 78 & $<0 \cdot 0001$ & $0 \cdot 30$ \\
\hline & \begin{tabular}{|l|} 
Physical score \\
(17 items)
\end{tabular} & $3 \cdot 88+/-0 \cdot 79$ & $4 \cdot 04+/-0 \cdot 74$ & 78 & $0 \cdot 0003$ & $0 \cdot 92$ \\
\hline & $\begin{array}{l}\text { Communication } \\
\text { score ( } 7 \text { items) }\end{array}$ & $2 \cdot 66+/-0 \cdot 76$ & $3 \cdot 04+/-0 \cdot 85$ & 78 & $<0 \cdot 0001$ & $0 \cdot 86$ \\
\hline & \begin{tabular}{|l|} 
Psychosocial score \\
(11 items)
\end{tabular} & $3 \cdot 63+/-0 \cdot 88$ & $3 \cdot 72+/-0 \cdot 81$ & 78 & $0 \cdot 23$ & $0 \cdot 07$ \\
\hline & \begin{tabular}{|l|} 
Energy score \\
(4 items)
\end{tabular} & $3 \cdot 77+/-0 \cdot 94$ & $3.92+/-0.91$ & 78 & $0 \cdot 11$ & $0 \cdot 31$ \\
\hline \multicolumn{7}{|l|}{$\begin{array}{l}\text { Nonverbal cognitive } \\
\text { functioning }\end{array}$} \\
\hline NVLT & $\begin{array}{l}\text { Hits minus } \\
\text { false alarms }\end{array}$ & $13 \cdot 53+/-9 \cdot 26$ & $18 \cdot 29+/-11 \cdot 59$ & 76 & $<0 \cdot 0001$ & $0 \cdot 26$ \\
\hline \multirow{2}{*}{$\begin{array}{l}\text { TMT - sec until } \\
\text { completion }\end{array}$} & $\begin{array}{l}\text { version A } \\
(\text { max. 180 sec) }\end{array}$ & $76 \cdot 54+/-35 \cdot 20$ & $63 \cdot 39+/-30 \cdot 39$ & 70 & $0 \cdot 0003$ & $0 \cdot 99$ \\
\hline & $\begin{array}{l}\text { version B } \\
\text { (max. 300 sec) }\end{array}$ & $175 \cdot 43+/-54 \cdot 00$ & $155 \cdot 15+/-61 \cdot 09$ & 33 & $0 \cdot 0325$ & $0 \cdot 65$ \\
\hline
\end{tabular}




\begin{tabular}{|c|c|c|c|c|c|c|}
\hline & & pre 3 weeks waiting & post 3 weeks SLT & & $\begin{array}{l}\text { Comparison of pre to } \\
\text { post } 3 \text { weeks of SLT }\end{array}$ & $\begin{array}{l}\text { Group difference } \\
\text { (SLT vs. control group): } \\
\text { Comparison of pre to } \\
\text { post } 3 \text { weeks of SLT }\end{array}$ \\
\hline & & $\mathrm{M}+/-\mathrm{SD}$ & $\mathrm{M}+/-\mathrm{SD}$ & $\mathrm{n}$ (post 3 weeks SLT) & p-value & p-value \\
\hline & & $\begin{array}{c}\text { (data also reported } \\
\text { in Table 2) }\end{array}$ & & & & \\
\hline \multicolumn{7}{|l|}{ Stroke severity } \\
\hline $\begin{array}{l}\text { modified Rankin } \\
\text { Scale }\end{array}$ & score (range: 0-6) & $2 \cdot 41+/-0.96$ & $2 \cdot 23+/-0.89$ & 78 & $0 \cdot 0073$ & $0 \cdot 09$ \\
\hline
\end{tabular}

M = mean; SD = standard deviation; SLT = speech and language therapy; ANELT = Amsterdam Nijmegen Everyday Language Test;

SAPS = Sprachsystematisches Aphasiescreening [langugage-systematic aphasia screening]; SAQOL-39 = Stroke and Aphasia Quality of Life Scale-39;

CETI = Communicative Effectiveness Index; NVLT = Nonverbal Learning Test; TMT = Trail Making Test; 